\title{
An Evolutionary Approach to the Multidepot Capacitated Arc Routing Problem
}

\author{
Lining Xing, Philipp Rohlfshagen, Yingwu Chen, and Xin Yao, IEEE Fellow
}

\begin{abstract}
The capacitated arc routing problem (CARP) is a challenging vehicle routing problem with numerous real world applications. In this paper, an extended version of CARP, the multidepot capacitated arc routing problem (MCARP), is presented to tackle practical requirements. Existing CARP heuristics are extended to cope with MCARP and are integrated into a novel evolutionary framework: the initial population is constructed either by random generation, the extended random path-scanning heuristic, or the extended random Ulusoy's heuristic. Subsequently, multiple distinct operators are employed to perform selection, crossover, and mutation. Finally, the partial replacement procedure is implemented to maintain population diversity. The proposed evolutionary approach (EA) is primarily characterized by the exploitation of attributes found in nearoptimal MCARP solutions that are obtained throughout the execution of the algorithm. Two techniques are employed toward this end: the performance information of an operator is applied to select from a range of operators for selection, crossover, and mutation. Furthermore, the arc assignment priority information is employed to determine promising positions along the genome for operations of crossover and mutation. The EA is evaluated on 107 instances with up to 140 nodes and 380 arcs. The experimental results suggest that the integrated evolutionary framework significantly outperforms these individual extended heuristics.
\end{abstract}

Index Terms-Capacitated arc routing problem, combinatorial optimization, evolutionary algorithms, time-limited service.

\section{INTRODUCTION}

$\mathbf{T}$ HE CAPACITATED arc routing problem (CARP) deals with undirected networks where each edge has a pre-

Manuscript received January 22, 2009, revised April 23, 2009 and July 15, 2009. First version published December 11, 2009; current version published May 28, 2010. This work was supported by the China Scholarship Council Grant No. 2007 103861, the National Natural Science Foundation of China Grant Nos. 70971 131, 70703 036, 70601 035, 70801 062, and 70901074 , and the Engineering and Physical Sciences Research Council Grant No. EPE058884-1 for "Evolutionary Algorithms for Dynamic Optimization Problems: Design, Analysis, and Applications."

L. Xing is with the College of Information Systems and Management, National University of Defense Technology, Changsha 410073, China (e-mail: xinglining@gmail.com).

P. Rohlfshagen is with the Center of Excellence for Research in Computational Intelligence and Applications, School of Computer Science, University of Birmingham, Birmingham B15 2TT, U.K. (e-mail: p.rohlfshagen@cs.bham.ac.uk).

Y. Chen is with the Department of Management Science and Engineering, College of Information Systems and Management, National University of Defense Technology, Changsha 410073, China (e-mail: chen.nudt@gmail.com)

$\mathrm{X}$. Yao is with the Center of Excellence for Research in Computational Intelligence and Applications (CERCIA), School of Computer Science, University of Birmingham, Birmingham B15 2TT, U.K. (e-mail: x.yao@cs.bham.ac.uk).

Color versions of one or more of the figures in this paper are available online at http://ieeexplore.ieee.org.

Digital Object Identifier 10.1109/TEVC.2009.2033578 defined traversal cost and some edges are required to be traversed (serviced) by some vehicle. There is a single depot which contains a fleet of identical vehicles, each with limited capacity. The objective of CARP is to determine a set of feasible vehicle trips of minimum total cost, such that every trip starts and ends at the depot, the total demand covered by each trip must not exceed the vehicle's capacity, and each required edge is serviced by a single trip.

The CARP has raised a growing interest in the last two decades because of important applications. As mentioned in the literature, CARP arises naturally in various industrial settings such as the planning of mail delivery [1] or school bus services [2], the routing of street sweepers [3], waste collection vehicles [4], gritting trucks [5] or snow plows [6], and the inspection of gas pipelines [7], oil pipelines [8] or electric power lines [9]. In order to make this paper more concrete and without loss of generality, examples are inspired by winter gritting.

To the best of our knowledge, Lacomme et al. [10] proposed the most recent version of CARP, the extended CARP (ECARP), in 2004. The authors considered the following four extensions: 1) mixed multigraph with different links (edges, arcs, and parallel links); 2) two distinct costs per link (deadheading and collecting); 3) prohibited turns and turn penalties; and 4) maximum trip length (an upper limit on the cost of trips). Here, deadheading means traveling without service. The number of vehicles is not specified and the problem definition potentially allows for an infinite number of vehicles as long as the single objective value is optimized [10]. We believe this to be impractical and chose to impose a limit on this number. This change, among multiple additional modifications, leads to the multidepot capacitated arc routing problem (MCARP) which is the focus of this paper.

Similar to ECARP, MCARP is modeled as a mixed multigraph with different links. Two distinct costs are predefined for each link, prohibited turns, and turn penalties are considered, no demand may exceed the vehicle's capacity, all vehicles are homogeneous, and no split gritting is allowed. MCARP differs from ECARP as it considers the maximum service time as well as multiple depots. In marginal winter climates, precautionary gritting ought to be finished by the highway management departments before the morning traffic [11]. For this reason, the maximum service time should be considered to guarantee successful service. As mentioned in [10], the maximum trip length is predefined for any trip, whilst the cost of every trip comprises collecting costs and deadheading 
costs. It is difficult to convert this mixed cost to service time. In MCARP, service time is predefined simply as the vehicle travel time (this is equivalent to the total deadheading cost of trips). This restriction on the service time places hard constraints on the problem: if the road network is large or the service time is small, some required roads cannot be serviced because of their long distance from the depot. In order to guarantee the availability of services, the extension to multiple depots is taken into account in MCARP.

The additional considerations introduce further complexities to an already complex problem. For instance, the introduction of multiple depots significantly enlarges the solution space: suppose the number of vehicles is $a$, then there are $a$ trips in most CARP solutions [10]. Further suppose the number of optional solutions of the $i$ th trip to be $Q_{i}$, and there are generally $\prod_{i=1}^{a} Q_{i}$ solutions in the solution space of CARP/ECARP. If there are $b$ depots, each trip can start from any of the depots, so the number of solutions of the $i$ th trip is $b Q_{i}$, then there are normally $b^{a}\left(\prod_{i=1}^{a} Q_{i}\right)$ solutions in the solution space of MCARP. In total, the solution space of ECARP is identical to that of CARP whereas the solution space of MCARP is about $b^{a}$ times than that of CARP. Furthermore, the complicated constraints of MCARP render a large number of potential solutions infeasible; the violation of any of the numerous constraints (such as, the vehicle's capacity, the number of vehicles, or the maximum service time) would result in an infeasible solution. Finally, it should be noted that MCARP is NP-hard. This follows from the fact that the basic CARP is NP-hard [10] and that it is possible to reduce MCARP to the basic CARP.

Unfortunately, good quality solutions to MCARP cannot be found efficiently by existing algorithms. In this paper, we examine the effectiveness of existing classical heuristics as well as metaheuristics. First, three classical heuristics, originally developed for CARP, were extended to MCARP. For some of the MCARP instances considered in this paper, these extended heuristics cannot guarantee to find a feasible solution. For example, one of the heuristics, extended augment-merge, finds a feasible solution for only 15 out of 87 MCARP instances considered. Furthermore, the significant size of the infeasible region of the search space makes it difficult to find high-quality solutions by using existing metaheuristics directly. In particular, using a standard genetic algorithm (GA) on MCARP, it proved rather difficult to generate feasible individuals (solutions) as the random initialization used by the starting population and the poor quality of the initial population would subsequently influence the performance of the GA. Therefore, a novel evolutionary approach (EA) is constructed in this research: some classical heuristics are integrated into a canonical evolutionary framework and two distinct kinds of heuristic information are learned from the near-optimal MCARP solutions that are obtained throughout the execution of the algorithm. This information is subsequently employed to guide the evolutionary process.

The remainder of this paper is organized as follows. Section II reviews some recent work related to CARP. Section III presents the formulation of MCARP and several constructive heuristics are proposed for MCARP in Section
IV. Section V introduces the proposed EA in detail. The performance of the proposed methods is evaluated in Section VI, and some concluding remarks and directions for future work are summarized in Section VII.

\section{LITERATURE REVIEW}

Some representative variations of the CARP may be summarized as follows [12]: vehicle routing problem (VRP) [13], Chinese postman problem (CPP) [14], rural postman problem (RPP) [15], stochastic arc routing problem [16], capacitated Chinese postman problem [17], traveling salesman problem [18], general routing problem [19], and periodic arc routing problem [20]. The performance of classical heuristics and metaheuristics is generally evaluated by lower bounds (LBs). LBs for CARP are usually estimated by: matching LB [12], node scanning LB [17], node duplication LB [21], matching node scanning LB [22], multiple cuts node duplication LB (MCNDLB) [23], and linear programming formulations [24]. MCNDLB performs at least as well as the existing bound for CARP [23].

Exact methods for CARP such as branch-and-bound [25] are still limited to 20-30 edges [10]. The large instances need to be tackled by heuristics like augment-merge [12], path-scanning [26], construct-and-strike [27], Ulusoy's tour splitting method [28], and augment-insert [29]. Final experimental results suggest that heuristics produce fairly good solutions. Nevertheless, better solutions can be obtained by metaheuristics, i.e., tabu search [30-32], variable neighborhood descent method [33], guided local search [34], EA [20], [35], memetic algorithms (MA) [10], [36], simulated annealing [37], GA [38], and ant colony optimization [39].

Hierarchical and integrated approaches are different ways to solve CARP instances. In hierarchical approaches, cluster and route are treated separately [40]. A route first cluster second algorithm [40] builds an Euler tour over all arcs with positive demands. If the obtained tour is one connected graph, then the CPP algorithm is applied to produce an optimal set of vehicle routes. Otherwise, the RPP algorithm is applied to produce the final solution. In a cluster first route second algorithm [41], arcs are clustered into groups by considering the weight constraint and routes calculated using the CPP algorithm. The integrated approach was applied by considering cluster and route at the same time. Branda and Eglese [31] constructed the deterministic tabu search algorithm and obtained excellent solutions in reasonable computational time. Beullens et al. [34] developed a guided local search and achieved some highquality solutions in the limited computational time. Finally, Lacomme et al. [38] constructed the multiobjective GA and got excellent performance both in terms of solution quality and computational efficiency.

In terms of multiple depots, many scholars have paid more attention to multidepot vehicle routing problems (MDVRP), a problem formulated by Sumichrast and Markham [42] in 1995. A number of heuristic approaches were developed to deal with the MDVRP [43-47]. Nevertheless, contrary to the VRP, in which products are delivered to client nodes in the network, the CARP consists of visiting a subset of edges (arcs), and 
TABLE I

Glossary of MATHEMATICAL Symbols USED IN THIS PAPER

\begin{tabular}{l|l}
\hline Symbol & Meaning \\
\hline$G_{U}=(V, E)$ & Undirected connected graph. \\
$G_{D}=(V, A)$ & Directed connected graph. \\
$V$ & Set of $N_{V}$ nodes. \\
$E$ & Set of $N_{E}$ edges. \\
$A$ & Set of $N_{A}$ arcs. \\
$R$ & Set of $N_{R}$ required links $R \subseteq A(R \subseteq E)$. \\
$d(u)$ & Deadheading (traveling without gritting) cost of link $u$. \\
$s(u)$ & Additional service (gritting) cost of required link $u$. \\
$q(u)$ & Gritting demand of required link $u$. \\
$p e n(u, v)$ & Penalty occurs from arc $u$ to arc $v$. \\
$N_{1}$ & Number of depots. \\
$N_{2}$ & Number of trucks. \\
$Q$ & Capacity of trucks. \\
$S$ & Average speed of trucks. \\
$T$ & Maximal service time. \\
$C$ & Maximal trip length. \\
$\alpha$ & Deadheading cost conversion coefficient. \\
$L$ & Set of vehicle routes $L=\left\{l_{1}, l_{2}, \ldots, l_{N_{2}}\right\}$. \\
$l_{j}$ & Vehicle route $l_{j}=\left\{\mu_{1 j}, \mu_{2 j}, \ldots, \mu_{\left(m_{j}\right) j}\right\}$. \\
$m_{j}$ & Number of links in route $l_{j}$. \\
$\mu_{i j}$ & $i$ th link in vehicle route $l_{j}$. \\
$f_{j}\left(\mu_{i j}\right)$ & Service indicator of link $\mu_{i j}$. \\
$D\left(l_{j}\right)$ & Total deadheading cost of route $l_{j}$. \\
$S\left(l_{j}\right)$ & Total service cost of route $l_{j}$. \\
$P\left(l_{j}\right)$ & Total penalty of route $l_{j}$. \\
\hline &
\end{tabular}

hence the heuristic algorithm proposed to the MDVRP cannot be directly applied to deal with the MCARP. Research on MCARP (or similar extensions) is considerably less. Amberg et al. [49] proposed a tabu search using capacitated trees to solve the multiple center CARP. However, in their MCARP model, only a simplified cost is predefined to every edge (arc), prohibited turns and turn penalties are not considered, and the maximum service time is not taken into account either.

This brief review suggests that existing approaches cannot be employed directly to deal with MCARP. It is thus necessary to develop novel approaches to tackle MCARP and this motivates the work presented in this paper.

\section{PROBLEM Formulation OF MCARP}

The previous sections of this paper informally described CARP, ECARP, and MCARP. In this section, we will formally describe each problem and elaborate further on the attributes unique to MCARP. We have listed the attributes of different problems in itemized form to allow a direct comparison among these three problem variants. Table I provides the summary of symbols used in this paper.

The classical CARP is characterized as follows.

1) Inputs

a) An undirected connected graph is $G=(V, E)$.

b) Each arc $u \in E$ incurs a cost $d(u)$.

c) Each arc $u \in R$ has a demand $q(u)$.

d) One depot is available.

e) $N_{2}$ identical trucks are available.

f) The capacity of trucks is $Q$.

2) Outputs

a) An optimal set of vehicle routes is $L$.

b) Service indicators are $f_{j}\left(\mu_{i j}\right)$.
3) Objectives

$$
\min \sum_{j=1}^{N_{2}} D\left(l_{j}\right) .
$$

4) Constraints

a) Start and return the same depot.

b) Demand constraints.

c) No partial service.

The ECARP, an extended version of CARP, has the following attributes.

1) Inputs

a) A directed connected graph is $G=(V, A)$.

b) Each arc $u \in A$ incurs a deadheading cost $d(u)$.

c) Each arc $u \in R$ has an additional service cost $s(u)$.

d) Each arc $u \in R$ has a demand $q(u)$.

e) $\operatorname{pen}(u, v)$ occurs from arc $u \in A$ to arc $v \in A$.

f) One depot is available.

g) $N_{2}$ identical trucks are available.

h) The capacity of trucks is $Q$.

i) The maximum trip length is $C$.

2) Outputs

a) An optimal set of vehicle routes is $L$.

b) Service indicators are $f_{j}\left(\mu_{i j}\right)$.

3) Objectives

$$
\min \sum_{j=1}^{N_{2}}\left\{D\left(l_{j}\right)+S\left(l_{j}\right)+P\left(l_{j}\right)\right\} .
$$

4) Constraints

a) Start and return the same depot.

b) Demand constraints.

c) No partial service.

d) Trip length constraints.

Finally, MCARP, which further extends ECARP, may be summarized as follows.

1) Inputs

a) A directed connected graph is $G=(V, A)$.

b) Each arc $u \in A$ incurs a deadheading cost $d(u)$.

c) Each arc $u \in R$ has an additional service cost $s(u)$.

d) Each arc $u \in R$ has a demand $q(u)$.

e) $\operatorname{pen}(u, v)$ occurs from arc $u \in A$ to arc $v \in A$.

f) $N_{1}$ identical depots are available.

g) $N_{2}$ identical trucks are available.

h) The capacity of trucks is $Q$.

i) The average speed of trucks is $S$.

j) The maximal service time is $T$.

k) Deadheading cost conversion coefficient $\alpha$.

2) Outputs

a) An optimal set of vehicle routes is $L$.

b) Service indicators are $f_{j}\left(\mu_{i j}\right)$.

c) There is a start depot of each vehicle route.

3) Objectives

$$
\min \sum_{j=1}^{N_{2}}\left\{D\left(l_{j}\right)+S\left(l_{j}\right)+P\left(l_{j}\right)\right\} .
$$


Step 1. Initialize the best solution, set the objective of best solution as infinite.

Step 2. Select one rule to construct the solution. Generate a random integer $r \in[1<50]$. If $r \leq 5$, then select the $r^{t h}$ rule; else select the sixth rule.

Step 3. Construct a feasible solution using the selected rule of Step 2.

Step 3.1. Select a convenient depot. The depot closest to any required arc which has not yet serviced is selected as current depot. If there are many suitable depots, then select one randomly.

Step 3.2. Select the next feasible required arc using the current rule.

Step 3.3. Join the selected arc of Step 3.2 to the current tour.

Step 3.4. If both capacity and service time are not exhausted, go to Step 3.2.

Step 3.5. If some required arcs are still not serviced, go to Step 3.1.

Step 3.6. If the current solution is better than the best solution, then update the best solution.

Step 4. If the number of iterations is less than 5000, then go to Step 2; else record the best solution and stop.

Fig. 1. Pseudocode of extended random path-scanning heuristic.

\section{4) Constraints}

a) Start and return the same depot.

b) Demand constraints.

c) No partial service.

d) Service time constraints.

It should be noted that if each truck has to return to the nearest available depot, then it will produce another interesting variant of the MCARP. After some small modifications (only the split procedure needs to be modified), our methods could still cope with this new variant. This novel variant will be farther studied in the future research. Additional MCARP central concepts are further elaborated and summarized in Appendix A.

In MCARP, there are multiple different costs for each vehicle route. The total deadheading (i.e., traversal without service) cost $D\left(l_{j}\right)$ is computed as

$$
D\left(l_{j}\right)=\sum_{i=1}^{m_{j}} d\left(\mu_{i j}\right) .
$$

The total service cost $S\left(l_{j}\right)$ is determined as

$$
S\left(l_{j}\right)=\sum_{i=1}^{m_{j}} s\left(\mu_{i j}\right) f_{j}\left(\mu_{i j}\right)
$$

and finally, the total penalty $P\left(l_{j}\right)$ is

$$
P\left(l_{j}\right)=\sum_{i=1}^{m_{j}-1} \operatorname{pen}\left(\mu_{i j}, \mu_{(i+1) j}\right) .
$$

There are five kinds of constraints considered in this paper. These are as follows.

1) Any route must start and return the same depot.

2) The total demand processed by each trip must not exceed the capacity $Q$. For every route $l_{j}$

$$
\sum_{i=1}^{m_{j}} q\left(\mu_{i j}\right) f_{j}\left(\mu_{i j}\right) \leq Q, 1 \leq j \leq N_{2} .
$$

3) Each required arc must be serviced by one truck exactly once (i.e., no partial service).
4) The total length of each trip must not exceed the maximum trip length $C$

$$
\max _{1 \leq j \leq N_{2}}\left\{D\left(l_{j}\right)+S\left(l_{j}\right)\right\} \leq C .
$$

5) The total service time of every truck must not exceed the maximum service time $T$

$$
\max _{1 \leq j \leq N_{2}}\left\{\sum_{i=1}^{m_{j}} d\left(\mu_{i j}\right)\right\} \leq \frac{S \times T}{\alpha} .
$$

\section{CONSTRUCTIVE HeURistics FOR THE MCARP}

The following classical heuristics, path-scanning [26], augment-merge [12], and the Ulusoy's heuristic [28] not only deal efficiently with CARP, but also have been extended to deal with ECARP [12]. In this paper, we further extend these heuristics to tackle MCARP. As mentioned in [12], the extended arc-to-arc distance matrix is employed to handle forbidden turns and Dijkstra's algorithm [50] is applied to precompute the shortest feasible path between all pairs of arcs.

\section{A. Extended Random Path-Scanning}

The extended random path-scanning (ERPS) constructs one tour at a time. When constructing a tour, it joins the most promising arc to the sequence of arcs until capacity $Q$ or service time $T$ is exhausted. For a sequence ending at arc $u$, it determines the set $M$ of arcs closest to $u$, not serviced and feasible for $Q$ and $T$. The following six rules are employed to select the next arc $v$ in $M$.

1) Rl: Dearest arc, maximize $d(v)+s(v)-\operatorname{pen}(u, v)$.

2) R2: Cheapest arc, minimize $d(v)+s(v)+$ pen $(u, v)$.

3) R3: Maximize the yield $q(v) /(d(v)+s(v)+$ pen $(u, v))$.

4) R4: Minimize the yield $q(v) /(d(v)+s(v)-$ pen $(u, v))$.

5) R5: Use R1 if the vehicle is less than half-full, else use $\mathrm{R} 2$.

6) R6: Use the above five rules randomly. 
Step 1. Initialization Operation: Construct a tour for every required edge and sort all tours in order to decreasing cost. Note: Each tour only has one required edge which needs to be serviced.

Step 2. Augment Operation: Each tour tries to absorb another smaller tour if it is possible and feasible.

Step 3. Merge Operation: Concatenates any two trips with the largest positive saving subject to all constraints. The merge process is repeated until no further concatenations are possible.

Step 4. Record the resulting solution.

Fig. 2. Pseudocode of extended augment-merge heuristic.

Step 1. Initialize the best solution, set the objective of the best solution as infinite.

Step 2. Select a rule to construct the giant tour. Generate a random integer number $r \in$ [1 50 ], if $r \leq 5$, then select the $r^{t h}$ rule; else select the sixth rule.

Step 3. Using the selected rule of Step 2, construct a least-cost giant tour covering all required edges with relaxed vehicle capacity and service time.

Step 4. Split the obtained tour into smaller feasible tours (current solution), considering vehicle capacity and service time. If the resulting solution is better than the best one, then update the best solution.

Step 5. If the number of iterations is less than 5000, then go to Step 2; else record the best solution and stop.

Fig. 3. Pseudocode of extended random Ulusoy's heuristic.

The first four rules are individual rules, while the last two rules are compound rules. Rule R6 is constructed as follows:

$$
\mathrm{R} 6= \begin{cases}\mathrm{R} 1, & 0 \leq r_{i}<0.2 \\ \mathrm{R} 2, & 0.2 \leq r_{i}<0.4 \\ \mathrm{R} 3, & 0.4 \leq r_{i}<0.6 \\ \mathrm{R} 4, & 0.6 \leq r_{i}<0.8 \\ \mathrm{R} 5, & 0.8 \leq r_{i}<1\end{cases}
$$

where $r_{i} \in[0,1)\left(1 \leq i \leq N_{R}\right)$ denotes a randomly chosen number. It other words, rule R6 randomly selects one rule from R1 to R5 at each decision point. The ERPS can quickly obtain one near-optimal solution thanks to compensation effects of these different rules. The pseudocode of ERPS is displayed in Fig. 1.

\section{B. Extended Augment-Merge}

Initialization, augment, and merge are three phases in the EAM heuristic. The initialization phase constructs $N_{R}$ tours (one per required arc) and sorts the resulting tours in decreasing cost order. In the augment phase, tour $T_{i}$ absorbs another smaller tour $T_{j}$ if it satisfies the constraint of capacity $Q$ and all the required arcs of $T_{j}$ are on the deadheading path of $T_{i}$. In the merge phase, the heuristic evaluates possible concatenations of any two tours and joins the two tours with the largest positive saving subject to constraints of maximum service time $T$ and capacity $Q$. This merge operation is repeated until no further concatenation is possible. EAM is a deterministic approach and its pseudocode is displayed in Fig. 2.

\section{Extended Random Ulusoy's Heuristic}

The extended random Ulusoy's heuristic (ERUH) temporarily relaxes capacity $Q$ and service time $T$ to construct a leastcost tour $C$ covering all required arcs (a giant tour). This phase is implemented by executing ERPS with a big value of $Q$ and $T$. The (giant) tour $C$ is optimally split into some small feasible tours (the proposed split procedure is explained later). In order to achieve better results, users can keep all tours obtained by ERPS, split them, and return the best solution. The pseudocode of ERUH is displayed in Fig. 3.

\section{Proposed Evolutionary Framework}

This proposed evolutionary framework is characterized by the integration of the three extended heuristics discussed in previous sections. As mentioned before, the significant size of the infeasible region in the MCARP search space poses the difficulty of finding good quality feasible solutions using the EA alone. The integration of classical heuristics (heuristics) into the evolutionary framework addresses this issue. In addition, the near-optimal solutions obtained throughout the search are analyzed to extract information that can be used to guide the subsequent search (heuristic information). We subsequently label our approach as HHEA. The computational flow of HHEA is shown in Fig. 4. In the initialization phase, most individuals are generated by ERPS and ERUH, while in the mutation phase, the 2-Opt heuristic is employed to implement the mutation on one or two trips. The 2-Opt heuristic eliminates two edges and reconnects the two resulting paths in a novel way to obtain a new tour.

Many papers have reported on applications of the interaction between evolution and learning [51-55]. These approaches keep useful features of previous individuals to improve the performance of current individuals and exploit profitable individuals from the previous population to populate the memory (train a learning module). According to [55], such approaches outperform traditional evolutionary algorithms on several 


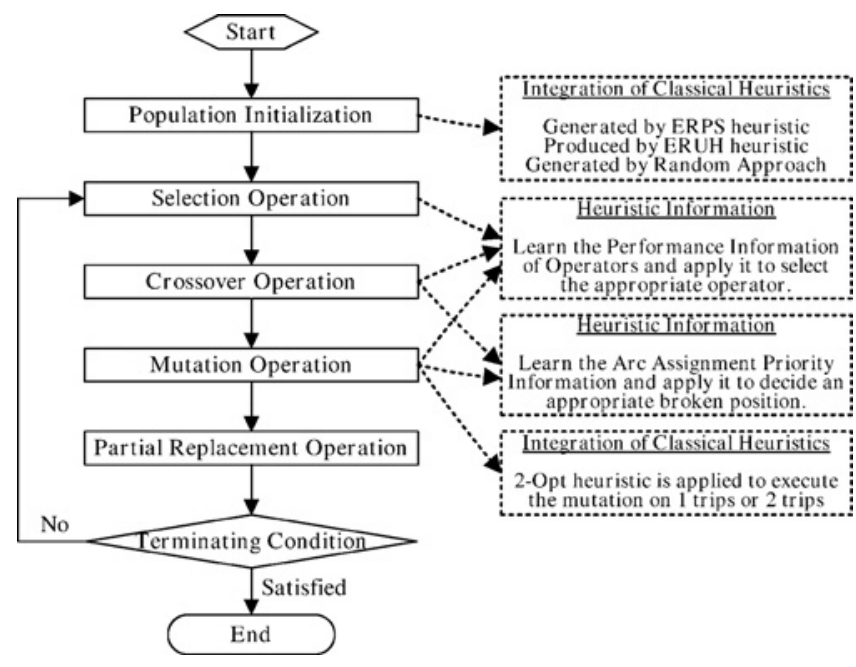

Fig. 4. Computational flow of this proposed evolutionary framework.

benchmarks (e.g., flexible job shop scheduling problem). In a similar fashion, HHEA extracts instance-specific information from near-optimal MCARP solutions, obtained throughout the search process, to guide the subsequent evolution. This process is elaborated further in the subsequent sections.

\section{A. Heuristic Information}

In order to improve the performance of HHEA, various operators are employed to execute the operations of selection, crossover, and mutation. One cannot expect a single operator to perform equally well on a range of different instances, and therefore, it is necessary to discover which operators are efficient for the current instance. We call this information the performance information of operators (PIO). The success of each operator is judged by its ability to produce an individual that can be inserted into the current population (the insertion policy is explained in Section V-H). In HHEA, six distinct mutation operators are employed. Suppose $N(i)$ denotes the accumulated number of successful mutations by the $i$ th mutation operator, then $N(i)$ may be considered as the performance of the $i$ th mutation operator. If the current mutation operation is successful and it was executed using the $i$ th mutation operator, and then $N(i)$ will be increased by 1 . For the next mutation, the mutation operator is selected randomly according to following probability:

$$
P(i)=\frac{N(i)}{\sum_{i=1}^{6} N(i)}
$$

where $P(i)$ denotes the probability of selecting the $i$ th operator.

The second measure is called the arc assignment priority information (AAPI) which is applied to establish a beneficial order for the given arcs. A matrix $M_{a}$ with size $N_{A} \times \mathrm{Dim}$ is defined for the AAPI, where Dim denotes the predefined row dimension of matrix $M_{a}$. A simple example of an AAPI matrix $\left(N_{A}=4\right.$ and $\left.\operatorname{Dim}=6\right)$ is shown in Table II. In this case, the first three $(0.5 \times \mathrm{Dim})$ rows of each line denote the three closest arcs to the corresponding arc. For example, the number 1 in the first row of the second line denotes that the closest arc to arc 2 (corresponding to the second line) is arc 1
TABLE II

EXAMPLE OF ARC ASSIGNMENT PRIORITY INFORMATION MATRIX

\begin{tabular}{l|c|c|c|c|c|c}
\hline Arcs & Row 1 & Row 2 & Row 3 & Row 4 & Row 5 & Row 6 \\
\hline 1 & 2 & 3 & 4 & 12 & 8 & 10 \\
\hline 2 & 1 & 4 & 3 & 6 & 11 & 13 \\
\hline 3 & 1 & 4 & 2 & 9 & 10 & 11 \\
\hline 4 & 3 & 2 & 1 & 5 & 9 & 16 \\
\hline
\end{tabular}

(each arc is indexed from 1 to $N_{A}$ ), whereas number 3 in the third row of the second line indicates that the third closest arc to arc 2 is arc 3 . The last three rows of each line indicate the total number of appearances of a given sequence among the near-optimal solutions. For example, number 6 in the fourth row of the second line denotes the total number of times of the sequence $(2,1)$ appears among the near-optimal solutions obtained throughout the search (sequence $(2,1)$ means that arc 2 is serviced before arc 1).

In order to preserve some promising subsequences among current individuals, the AAPI is employed to select appropriate break points for crossover and mutation. If the number of times a given sequence appears is large, then the break points for this sequence is selected with a small probability. For example, if the current individual is $4 \rightarrow 3 \rightarrow 2 \rightarrow 1$, the appearance times of sequences $(4,3),(3,2)$, and $(2,1)$ are 5,11 , and 6 , respectively (obtained from Table II), and the broken position between sequences $(4,3),(3,2)$, or $(2,1)$ is selected with a probability of $0.5,0.07$, or 0.43 , respectively. The probabilities are computed as follows:

$$
\begin{array}{ccc}
5 & 11 & 6 \\
4 \rightarrow 3 & \rightarrow 2 & \rightarrow 1 \\
0.50 & 0.07 & 0.43
\end{array}
$$

Appearance times:

Inverse number $(-)$ :

Make it positive $(+12)$ :

Probability computation $(\div 14)$

$\begin{array}{rrr}5 & 11 & 6 \\ -5 & -11 & -6 \\ 7 & 1 & 6 \\ 0.5 & 0.07 & 0.43\end{array}$

According to our experimental results, an appropriate value for row dimension of AAPI matrix is 20 , and the AAPI is obtained from the top 30 individuals of the current population.

\section{B. Chromosome Structure and Evaluation}

Each chromosome $C$ is defined simply as a sequence of the $N_{R}$ required arcs, without trip delimiters, and with implicit shortest paths between consecutive arcs and may be viewed as a giant tour ignoring the capacity and service time constraints. The split procedure is then employed to obtain a feasible MCARP solution. The fitness $F(C)$ of individual $C$ is acquired by the split procedure, which minimizes the total cost subject to the sequence of arcs defined by individual $C$ and the number of trips. The number of trips is variable but cannot exceed the number of trucks $N_{2}$. The pseudocode of the split procedure is displayed in Fig. 5. This procedure runs in $O\left(N_{R} N_{2}\right)$ space and its complexity is $O\left(N_{R}^{2} N_{2}\right)$. This algorithm enumerates all subsequences $\left(C_{i}, \ldots, C_{j}\right)$ of $C$ that correspond to feasible trips and computes their total 


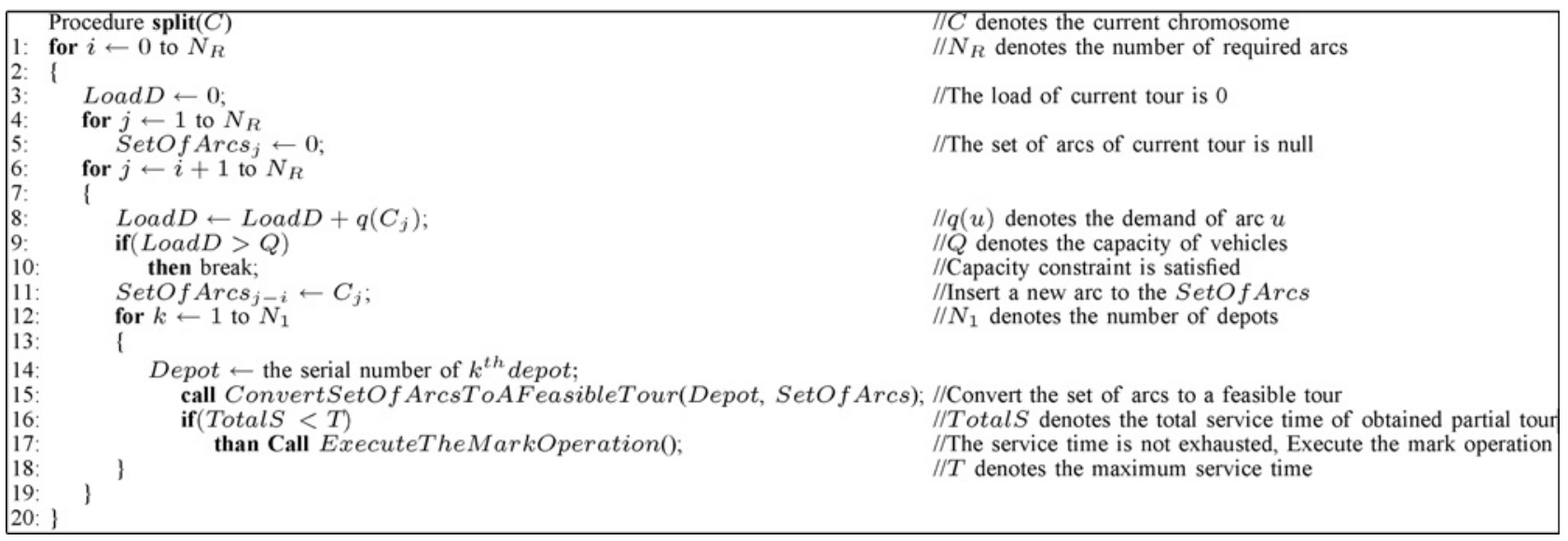

Fig. 5. Proposed split procedure working on a chromosome.

cost and total deadheading cost, while it enumerates all depots in the third loop; the split procedure first satisfies the constraint imposed by the maximum number of trucks and then finds the minimum total cost of the solutions. It should be noted that the operation ExecuteTheMarkOperation(), as shown in Fig. 5, is performed by the multimark algorithm, a simple example of which may be found in Appendix B.

\section{Population Initialization}

In the proposed evolutionary framework, both feasible and infeasible solutions are allowed to exist in the population. In order to penalize infeasible solutions, their fitness is doubled (MCARP is a minimization problem). The population consists exclusively of unique phenotypes and clones (identical solutions) are never accepted. Since the verification of unique phenotypes is computationally very expensive, an approximate but faster method is applied to guarantee all individuals among the population have different costs. Suppose $L_{b}$ and $U_{b}$ denote the LB and upper bound on the total cost of solutions, respectively. Here, $L_{b}$ is approximated by MCNDLB [23], and $U_{b}$ is empirically estimated via $U_{b}=5 L_{b}$. We experimentally established the interval $\left[L_{b}, U_{b}\right]$ to be divided into 10000 levels, and only the best solution in each subinterval is inserted into the current population.

The population is initialized using three different methods: random generation, ERPS heuristic, and ERUH heuristic. The quality of the initial population is improved significantly by ERPS and ERUH. However, many attempts may be required to add a new distinct chromosome to the population when the population size $\left(P_{S}\right)$ is large or the problem size is small. Therefore, the number of attempts to obtain one new individual is upper bounded by $N_{I}$ : if it turns out to be too difficult to achieve a sufficient number of initial individuals, the process of population initialization will be terminated after $N_{I}$ unsuccessful attempts. In this case, the value of $P_{S}$ will be reduced to the number of unique individuals generated already. The fitness evaluations in the population initialization phase are counted into the total number of fitness evaluations.

\section{Selection Operation}

In an iteration of the HHEA, two distinct chromosomes are selected to undergo crossover and mutation. The resultant individual is inserted into the current population if possible. The following two types of selection are used.

1) Binary Tournament: Selects two different chromosomes randomly and the least-cost one is kept.

2) Rank Order Selection: Selects the chromosome of rank $i$ (individuals are ranked according to their fitness) with probability

$$
P(i)=\frac{2\left(P_{S}-i+1\right)}{P_{S}\left(P_{S}+1\right)}
$$

\section{E. Crossover Operation}

The fitness (solution quality) of newly produced offspring is used to adjust the genetic operators, and hence to influence the search. However, since selection alone does not generate any novel individuals, its success rate is established once the individuals have been crossed over (which takes place immediately after selection). HHEA makes use of two different crossover operators, order crossover (OX) and linear order crossover (LOX). LOX is designed specifically for linear chromosomes and OX is used for circular permutations. These offspring resulting from the crossover event are evaluated by the proposed split procedure.

\section{F. Mutation Operation}

It has been demonstrated that the effectiveness of canonical GAs can be improved significantly by using a memetic approach: the algorithm's genetic operators are complimented by local search for improving overall performance [10]. With some probability, each offspring is converted into a solution to undergo mutation by means of local search, which scans pairs of arcs to evaluate the moves listed below where $x(y)$ denotes the arc serviced after arc $u(v)$ in trip $T_{1}\left(T_{2}\right)$.

1) Move 1: Invert $\operatorname{arc} u$ if it is a bidirectional arc.

2) Move 2: Move $u$ after $v$.

3) Move 3: Move adjacent $\operatorname{arcs}(u, x)$ after arc $v$.

4) Move 4: Swap $\operatorname{arcs} u$ and $v$. 


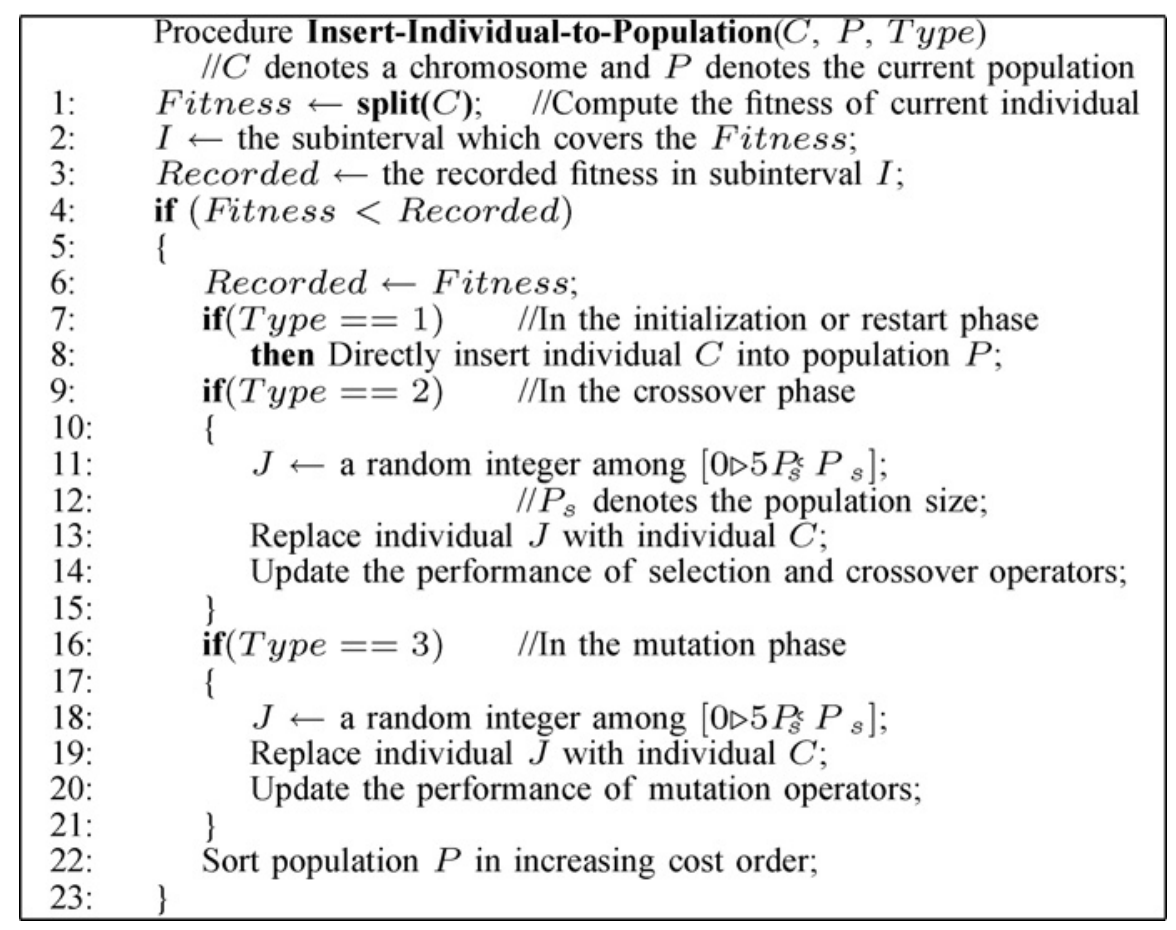

Fig. 6. Computational flow of inserting one individual into the population.

TABLE III

Strategy SETtings of THREe DifFERENT Versions of THE HHEA

\begin{tabular}{l|l|l|l}
\hline Phases & HHEA-1 & HHEA-2 & HHEA-3 \\
\hline \hline Selection & S1 & S2 & S2 \\
\hline Crossover & S1 + S3 & S2 + S3 & S2 +S4 \\
\hline Mutation & S1+S3 & S2 + S3 & S2+S4 \\
\hline
\end{tabular}

TABLE IV

PARAMETER SETTINGS OF HHEA

\begin{tabular}{c|l|c}
\hline Name & Role & Value \\
\hline \hline$P_{S}$ & Population Size & 200 \\
\hline$N_{I}$ & $\begin{array}{l}\text { Maximum number of attempts to get } \\
\text { each initial chromosome }\end{array}$ & 100 \\
\hline$R_{M}$ & $\begin{array}{l}\text { Local search rate in main phase and } \\
\text { restarts }\end{array}$ & 0.05 \\
\hline$N_{L}$ & $\begin{array}{l}\text { Fixed Number of attempts in each Local } \\
\text { search }\end{array}$ & 5 \\
\hline$N_{F}^{m}$ & $\begin{array}{l}\text { Maximum number of fitness } \\
\text { evaluations in main phase }\end{array}$ & 2000 \\
\hline$N_{R}$ & Maximum number of restarts & 5 \\
\hline$N_{S}$ & $\begin{array}{l}\text { Number of solutions replaced in each } \\
\text { restart }\end{array}$ & 20 \\
\hline$N_{F}^{r}$ & $\begin{array}{l}\text { Maximum number of fitness } \\
\text { evaluations per restart }\end{array}$ & 600 \\
\hline
\end{tabular}

5) Move 5: 2-Opt moves on one trip [10].

6) Move 6: 2-Opt moves on two trips [10].

The mutation operator then selects a type of move randomly. It then randomly produces $N_{L}$ optional moves and computes the improved objective of each move. Finally, the move that results in the best improvement is performed.
TABLE V

SUMMARY OF ABBREVIATIONS USED

\begin{tabular}{l|l}
\hline Symbols & Signification \\
\hline$S N$ & Serial number of examples. \\
\hline Name & Name of examples. \\
\hline$N_{P}$ & Number of penalties. \\
\hline$L_{b}$ & Lower bound of examples. \\
\hline Depots & Set of predefined depots. \\
\hline$F^{*}$ & Known optimal result of examples. \\
\hline$F_{A}$ & Average obtained result of examples. \\
\hline$F_{D}$ & Standard deviation of obtained results. \\
\hline$F_{A}^{E}$ & Error between $F_{A}$ and $L_{b}$. \\
\hline$F_{A}^{*}$ & Error between $F_{A}$ and $F^{*}$. \\
\hline$T_{A}$ & Average computational time. \\
\hline
\end{tabular}

\section{G. Partial Replacement Operation}

According to [10], many CARP instances can be solved by adding a fixed number of short restarts based on the partial replacement procedure (PRP) [56]. It has been demonstrated experimentally that PRP never degrades the worst cost, preserves the best solution, and obtains a better final solution [56]. In this paper, the same number of restarts and the same length of each restart are allocated to all examples.

\section{H. Insertion Policy}

The computational flow of inserting an individual (which has to be unique) into the population is displayed as Fig. 6 . In the initialization or restart phase, the new chromosome is inserted directly into population. In the crossover or mutation phase, the chromosome, whose total cost is larger than the median cost of the current population, is selected randomly from the population and is replaced by the new individual. 
TABLE VI

ATTRIBUTES OF MODIFIED MCARP INSTANCES GENERATED By BENCHMARK FILES (TOTAL 87 EXAMPLES)

\begin{tabular}{|c|c|c|c|c|c|c|c|}
\hline SN & Name & $N_{V}$ & $N_{A}$ & $N_{P}$ & $L_{b}$ & Depots & $\alpha$ \\
\hline C1 & E-GDB1 & 12 & 44 & 44 & 544.8 & 1 & 0.6 \\
\hline $\begin{array}{l}\mathrm{C} 2 \\
\mathrm{C} 3\end{array}$ & $\begin{array}{l}\text { E-GDB2 } \\
\text { E-GDB3 }\end{array}$ & $\begin{array}{l}12 \\
12\end{array}$ & $\begin{array}{l}52 \\
44\end{array}$ & $\begin{array}{l}44 \\
34\end{array}$ & $\begin{array}{l}616.4 \\
520.8\end{array}$ & 8 & $\begin{array}{l}0.6 \\
0.6\end{array}$ \\
\hline $\mathrm{C} 4$ & E-GDB4 & 11 & 38 & 44 & 523.2 & 1 & 0.6 \\
\hline C5 & E-GDB5 & 13 & 52 & 50 & $\begin{array}{l}704.8 \\
502\end{array}$ & 7 & 0.6 \\
\hline C6 & $\begin{array}{l}\text { E-GDB6 } \\
\text { E-GDB7 }\end{array}$ & 12 & 44 & $\begin{array}{l}44 \\
56\end{array}$ & $\begin{array}{c}592 \\
5576\end{array}$ & 7 & 0.6 \\
\hline $\begin{array}{l}\mathrm{C} 7 \\
\mathrm{C} 8\end{array}$ & $\begin{array}{l}\text { E-GDB7 } \\
\text { E-GDB8 }\end{array}$ & $\begin{array}{l}12 \\
27\end{array}$ & $\begin{array}{l}44 \\
92\end{array}$ & $\begin{array}{l}56 \\
50\end{array}$ & $\begin{array}{l}557.6 \\
489.2\end{array}$ & 5,17 & $\begin{array}{l}0.6 \\
0.6\end{array}$ \\
\hline C9 & $\begin{array}{l}\text { E-GDB9 } \\
\text { E-GDR } 19\end{array}$ & $\begin{array}{l}27 \\
12\end{array}$ & 102 & 50 & $\begin{array}{c}542 \\
528\end{array}$ & 26 & 0.6 \\
\hline $\begin{array}{l}\text { C11 } \\
\text { C11 }\end{array}$ & E-GDB11 & 22 & 90 & 36 & 718.4 & 12 & $\begin{array}{l}0.0 \\
0.6\end{array}$ \\
\hline C12 & $\begin{array}{l}\text { E-GDB12 } \\
\text { E-GDB13 }\end{array}$ & 13 & 46 & 12 & 786.4 & 5 & 0.6 \\
\hline C14 & E-GDB 14 & 7 & 42 & 40 & $\begin{array}{l}1035.0 \\
201.6\end{array}$ & 4 & $\begin{array}{l}0.0 \\
0.6\end{array}$ \\
\hline $\begin{array}{l}\text { C15 } \\
\text { C16 }\end{array}$ & $\begin{array}{l}\text { E-GDB15 } \\
\text { E-GDB16 }\end{array}$ & $\begin{array}{l}7 \\
8\end{array}$ & $\begin{array}{l}42 \\
56\end{array}$ & $\begin{array}{l}16 \\
40\end{array}$ & $\begin{array}{l}112.8 \\
241.2\end{array}$ & $\begin{array}{l}5 \\
1\end{array}$ & $\begin{array}{l}0.6 \\
0.6\end{array}$ \\
\hline C17 & E-GDB17 & 8 & 56 & 28 & $\begin{array}{l}170.4 \\
3256\end{array}$ & 1 & 0.6 \\
\hline $\begin{array}{l}\text { C19 } \\
\text { C19 }\end{array}$ & $\begin{array}{l}\text { E-GDB 18 } \\
\text { E-GDB19 }\end{array}$ & 8 & $\begin{array}{l}72 \\
22\end{array}$ & $\begin{array}{c}88 \\
6\end{array}$ & $\begin{array}{l}325.6 \\
91.6\end{array}$ & $\frac{1}{5}$ & 0.6 \\
\hline $\mathrm{C} 20$ & E-GDB 20 & 11 & 44 & 40 & 222.8 & 1 & 0.6 \\
\hline C21 & $\begin{array}{l}\text { E-GDB21 } \\
\text { E-GDB222 }\end{array}$ & 11 & $\begin{array}{l}66 \\
88\end{array}$ & 60 & $\begin{array}{l}313.2 \\
3016\end{array}$ & 1 & 0.6 \\
\hline $\mathrm{C} 23$ & $\begin{array}{l}\text { E-GDB 22 } \\
\text { E-GDB23 }\end{array}$ & 11 & $\begin{array}{l}08 \\
110\end{array}$ & 114 & $\begin{array}{l}39.0 \\
457.6\end{array}$ & 1 & $\begin{array}{l}0.6 \\
0.6\end{array}$ \\
\hline C24 & E-KSHS1 & 8 & 30 & 14 & 20006 & 5 & 0.05 \\
\hline $\begin{array}{l}225 \\
\mathrm{C} 26\end{array}$ & $\begin{array}{l}\text {-KSHS2 } \\
\text { E-KSHS3 }\end{array}$ & $\begin{array}{c}10 \\
6\end{array}$ & $\begin{array}{l}30 \\
30\end{array}$ & $\begin{array}{l}12 \\
18\end{array}$ & $\begin{array}{l}14608.8 \\
16463.6\end{array}$ & 1 & $\begin{array}{l}0.05 \\
0.05\end{array}$ \\
\hline $\begin{array}{l}\text { C27 } \\
\text { C28 }\end{array}$ & $\begin{array}{l}\text { E-KSHS4 } \\
\text { E-KSHS5 }\end{array}$ & $\begin{array}{l}8 \\
8\end{array}$ & $\begin{array}{l}30 \\
30\end{array}$ & $\begin{array}{l}24 \\
30\end{array}$ & $\begin{array}{l}17767.6 \\
20335.6\end{array}$ & 3 & 0.05 \\
\hline $\begin{array}{l}220 \\
\mathrm{C} 29\end{array}$ & E-KSHS6 & 9 & 30 & 30 & 20390 & 1 & 0.05 \\
\hline C31 & $\begin{array}{l}\text { E-VALIA } \\
\text { E-VAL1B }\end{array}$ & $\begin{array}{l}24 \\
24\end{array}$ & $\begin{array}{l}78 \\
78\end{array}$ & $\begin{array}{l}4 \\
4\end{array}$ & $\begin{array}{l}294.4 \\
294.4\end{array}$ & $\frac{13}{5}$ & $\frac{2}{2}$ \\
\hline $\begin{array}{l}\text { C32 } \\
\text { C33 }\end{array}$ & $\begin{array}{l}\text { E-VAL1C } \\
\text { E-VAL2A }\end{array}$ & $\begin{array}{l}24 \\
24\end{array}$ & $\begin{array}{l}78 \\
68\end{array}$ & $\begin{array}{l}4 \\
12\end{array}$ & $\begin{array}{l}346.4 \\
382\end{array}$ & $\begin{array}{c}5 \\
15\end{array}$ & $\frac{2}{2}$ \\
\hline & E-VAL2B & 24 & 68 & 12 & 386 & 20 & 2 \\
\hline $\begin{array}{l}\text { C35 } \\
\text { C36 }\end{array}$ & $\begin{array}{l}\text { E-VAL2C } \\
\text { E-VAL3A }\end{array}$ & 24 & $\begin{array}{l}68 \\
70\end{array}$ & 12 & 444.4 & 15 & 2 \\
\hline C37 & E-VAL3B & 24 & 70 & 10 & 131.6 & 11 & 2 \\
\hline & $\begin{array}{l}\text { E-VAL3C } \\
\text { E-VAL4A }\end{array}$ & 24 & 70 & 10 & 145.2 & 11 & 2 \\
\hline $\begin{array}{l}39 \\
\text { C40 }\end{array}$ & $\begin{array}{l}\text { E-VAL4A } \\
\text { E-VAL4B }\end{array}$ & $\begin{array}{l}41 \\
41\end{array}$ & $\begin{array}{l}138 \\
138\end{array}$ & $\begin{array}{l}4 \\
4\end{array}$ & $\begin{array}{l}090.8 \\
714.4\end{array}$ & 21 & 2 \\
\hline $\begin{array}{l}\text { C41 } \\
\text { C42 }\end{array}$ & $\begin{array}{l}\text { E-VAL4C } \\
\text { E-VAL4D }\end{array}$ & $\begin{array}{l}41 \\
41\end{array}$ & $\begin{array}{l}138 \\
138\end{array}$ & $\begin{array}{l}4 \\
4\end{array}$ & $\begin{array}{l}735.6 \\
784.4\end{array}$ & $\begin{array}{l}26 \\
27\end{array}$ & $\frac{2}{2}$ \\
\hline C43 & E-VAL5A & 34 & 130 & 10 & 737.2 & 12 & 2 \\
\hline $\begin{array}{l}\text { C44 } \\
\text { C45 }\end{array}$ & $\begin{array}{l}\text { E-VAL5B } \\
\text { E-VAL5C }\end{array}$ & 34 & $\begin{array}{l}130 \\
130\end{array}$ & $\begin{array}{l}10 \\
10\end{array}$ & $\begin{array}{l}742 \\
7816\end{array}$ & 21 & $\frac{2}{2}$ \\
\hline C46 & E-VAL5D & 34 & 130 & 10 & $\begin{array}{l}101.0 \\
862.8\end{array}$ & 6 & 2 \\
\hline C47 & E-VAL6A & 31 & 100 & 8 & 383.2 & 3 & 2 \\
\hline $\begin{array}{l}448 \\
C 49\end{array}$ & $\begin{array}{l}\text { E-VAL6B } \\
\text { E-VAL6C }\end{array}$ & 31 & 100 & $\begin{array}{l}8 \\
8\end{array}$ & 403.2 & 12 & 2 \\
\hline $\begin{array}{l}459 \\
\mathrm{C} 50\end{array}$ & $\begin{array}{l}\text { E-VAL6C } \\
\text { E-VAL7A }\end{array}$ & 40 & 132 & 8 & 498 & 11 & 2 \\
\hline C51 & E-VAL7B & 40 & 132 & 8 & 498 & 1 & 2 \\
\hline $\begin{array}{l}\text { C52 } \\
C 53\end{array}$ & $\begin{array}{l}\text { E-VAL7C } \\
\text { E-VAL8A }\end{array}$ & 40 & $\begin{array}{l}132 \\
136\end{array}$ & 8 & $\begin{array}{l}533.6 \\
698.8\end{array}$ & 1.28 & 2 \\
\hline C54 & E-VAL8B & 30 & 126 & 76 & 698.8 & 1,24 & 2 \\
\hline \begin{tabular}{l} 
C55 \\
\hdashline 56
\end{tabular} & $\begin{array}{l}\text { E-VAL8C } \\
\text { E-VAL9A }\end{array}$ & 30 & 126 & 76 & 748.8 & $\begin{array}{l}1,17 \\
18,34\end{array}$ & 2 \\
\hline $\begin{array}{l}50 \\
\text { C57 }\end{array}$ & $\begin{array}{l}\text { E-VAL9A } \\
\text { E-VAL9B }\end{array}$ & 50 & $\begin{array}{l}184 \\
184\end{array}$ & 22 & $\begin{array}{l}570 \\
564\end{array}$ & $\begin{array}{l}18,34 \\
1,38\end{array}$ & 2 \\
\hline $\begin{array}{l}588 \\
\text { C59 }\end{array}$ & $\begin{array}{l}\text { E-VAL9C } \\
\text { E-VAL9D }\end{array}$ & $\begin{array}{l}50 \\
50\end{array}$ & $\begin{array}{l}184 \\
184\end{array}$ & $\begin{array}{l}22 \\
22\end{array}$ & $\begin{array}{l}574.4 \\
622.8\end{array}$ & $\begin{array}{l}1,35 \\
1,37\end{array}$ & $\frac{2}{2}$ \\
\hline C60 & E-VAL10A & 50 & 194 & 28 & 755.2 & 13 & 2 \\
\hline $\begin{array}{l}\text { C61 } \\
\text { C62 }\end{array}$ & $\begin{array}{l}\text { E-VAL10B } \\
\text { E-VAL10C }\end{array}$ & 50 & $\begin{array}{l}194 \\
194\end{array}$ & 28 & $\begin{array}{l}771.2 \\
8024\end{array}$ & 37 & 2 \\
\hline C63 & E-VAL10D & 50 & 194 & 28 & 814.4 & 31 & 2 \\
\hline C64 & E-EGL-E1-A & 77 & 196 & 6 & 3376.6 & 19 & 0.2 \\
\hline $\begin{array}{l}\text { C65 } \\
\text { C6 }\end{array}$ & $\begin{array}{l}\text { E-EGL-El-B } \\
\text { E-EGL-E1-C }\end{array}$ & 77 & $\begin{array}{l}196 \\
196\end{array}$ & $\begin{array}{l}6 \\
6\end{array}$ & $\begin{array}{l}3 / 20.6 \\
4611.2\end{array}$ & 76 & $\begin{array}{l}0.2 \\
0.2\end{array}$ \\
\hline C67 & $\begin{array}{l}\text { E-EGL-E2-A } \\
\text {-EGL-F2 }\end{array}$ & 77 & 196 & 4 & $\begin{array}{l}4357.6 \\
5776\end{array}$ & 19 & 0.2 \\
\hline $\begin{array}{l}\text { C68 } \\
\text { C69 }\end{array}$ & E-EGL-E2-C & 77 & $\begin{array}{l}190 \\
196\end{array}$ & $\begin{array}{l}4 \\
4\end{array}$ & $\begin{array}{l}5715.6 \\
5369.8\end{array}$ & 44 & $\begin{array}{l}0.2 \\
0.2\end{array}$ \\
\hline $\begin{array}{l}\text { C70 } \\
\text { C71 }\end{array}$ & $\begin{array}{l}\text { E-EGL-E3-A } \\
\text { E-EGL-E3-E }\end{array}$ & 77 & 196 & $\frac{2}{2}$ & $\begin{array}{l}5297.4 \\
72336\end{array}$ & 19 & 0.2 \\
\hline C72 & E-EGL-E3-C & 77 & 196 & 2 & 7541.8 & 10 & 0.2 \\
\hline $\begin{array}{l}13 \\
\text { C } 74\end{array}$ & $\begin{array}{l}\text { E-EUL-E4-A } \\
\text { E-EGL-E4-B }\end{array}$ & 77 & $\begin{array}{l}190 \\
196\end{array}$ & $\begin{array}{l}20 \\
20\end{array}$ & $\begin{array}{l}5278 \\
5866\end{array}$ & $\begin{array}{r}1,20,41 \\
23,44,76\end{array}$ & $\begin{array}{l}0.2 \\
0.2\end{array}$ \\
\hline $\begin{array}{l}\text { C75 } \\
\text { C76 }\end{array}$ & $\begin{array}{l}\text { E-EGL-E4-C } \\
\text { E-FGL-S1-EA-A }\end{array}$ & $\begin{array}{l}77 \\
140\end{array}$ & $\begin{array}{l}196 \\
380\end{array}$ & 20 & $\begin{array}{l}6209.2 \\
4718\end{array}$ & $1,13,20,40$ & 0.2 \\
\hline C77 & E-EGL-S1-B & $\begin{array}{l}140 \\
140\end{array}$ & 380 & 2 & $\begin{array}{l}4373.4 \\
5373\end{array}$ & 85 & 0.2 \\
\hline C78 & E-EGL-S1-C & 140 & 380 & 2 & 7325.6 & 81 & 0.2 \\
\hline $\begin{array}{l}\text { C79 } \\
\text { 80 }\end{array}$ & E-EGL-S2-A & 140 & $\begin{array}{l}380 \\
380\end{array}$ & $\begin{array}{l}8 \\
8\end{array}$ & 8647 & $\begin{array}{l}1,63 \\
1,139\end{array}$ & 0.2 \\
\hline $\begin{array}{l}\text { C80 } \\
\text { C81 }\end{array}$ & $\begin{array}{l}\text { E-EGL-S2-B } \\
\text { E-EGL-S2-C }\end{array}$ & $\begin{array}{l}140 \\
140\end{array}$ & $\begin{array}{l}380 \\
380\end{array}$ & $\begin{array}{l}8 \\
8\end{array}$ & $\begin{array}{r}10291.2 \\
10680\end{array}$ & $\begin{array}{l}1,139 \\
72,123\end{array}$ & $\begin{array}{l}0.2 \\
0.2\end{array}$ \\
\hline C82 & E-EGL-S3-A & 140 & 380 & 8 & 8626 & 1,57 & 0.2 \\
\hline C83 & E-EGL-S3-B & 140 & 380 & 8 & 10640 & 1,43 & 0.2 \\
\hline C84 & E-EGL-S3-C & 140 & $\begin{array}{l}380 \\
300\end{array}$ & 8 & 12278.6 & 1,66 & 0.2 \\
\hline $\begin{array}{l}885 \\
C 86\end{array}$ & $\begin{array}{l}\text { E-EGL-S4-A } \\
\text { E-EGL-S4-B }\end{array}$ & $\begin{array}{l}140 \\
140\end{array}$ & $\begin{array}{l}380 \\
380\end{array}$ & $\begin{array}{l}4 \\
4\end{array}$ & $\begin{array}{l}10070.8 \\
108352\end{array}$ & $34,11,110$ & 0.2 \\
\hline $\begin{array}{l}\text { C87 } \\
\text { C }\end{array}$ & $\begin{array}{l}\text { E-EUL-S4-B } \\
\text { E-EGL-S4-C }\end{array}$ & $\begin{array}{l}140 \\
140 \\
\end{array}$ & 380 & $\begin{array}{l}4 \\
4\end{array}$ & 13325.2 & $6,89,112$ & $\begin{array}{l}0.2 \\
0.2 \\
\end{array}$ \\
\hline
\end{tabular}


TABLE VII

ATTRIBUTES OF MCARP INSTANCES WITH KNOWN OPTIMA (TOTAL 20 EXAMPLES)

\begin{tabular}{l|l|c|c|c|c|c}
\hline SN & Name & $N_{V}$ & $N_{A}$ & $N_{P}$ & $L_{b}$ & $F^{*}$ \\
\hline E1 & CASE-C101 & 40 & 132 & 0 & 164 & 180 \\
E2 & CASE-C102 & 40 & 132 & 0 & 218 & 262 \\
E3 & CASE-C103 & 40 & 132 & 0 & 174 & 210 \\
E4 & CASE-C104 & 40 & 132 & 0 & 218 & 262 \\
E5 & CASE-C201 & 49 & 168 & 0 & 224 & 240 \\
E6 & CASE-C202 & 49 & 168 & 0 & 296 & 324 \\
E7 & CASE-C203 & 49 & 168 & 0 & 224 & 272 \\
E8 & CASE-C204 & 49 & 168 & 0 & 296 & 324 \\
E9 & CASE-C301 & 70 & 246 & 0 & 328 & 360 \\
E10 & CASE-C302 & 70 & 246 & 0 & 424 & 492 \\
E11 & CASE-C303 & 70 & 246 & 0 & 348 & 412 \\
E12 & CASE-C304 & 70 & 246 & 0 & 424 & 492 \\
E13 & CASE-C401 & 91 & 324 & 0 & 432 & 480 \\
E14 & CASE-C402 & 91 & 324 & 0 & 556 & 668 \\
E15 & CASE-C403 & 91 & 324 & 0 & 464 & 532 \\
E16 & CASE-C404 & 91 & 324 & 0 & 556 & 668 \\
E17 & CASE-C501 & 100 & 360 & 0 & 484 & 540 \\
E18 & CASE-C502 & 100 & 360 & 0 & 630 & 754 \\
E19 & CASE-C503 & 100 & 360 & 0 & 514 & 550 \\
E20 & CASE-C504 & 100 & 360 & 0 & 630 & 754 \\
\hline
\end{tabular}

TABLE VIII

EXPERIMENTAL RESULTS OF EAM HEURISTIC

\begin{tabular}{|c|c|c|c|c|c|}
\hline SN & Name & $L_{b}$ & $F_{A}$ & $F_{A}^{E}(\%)$ & $T_{A}(S)$ \\
\hline $\mathrm{C} 2$ & E-GDB2 & 616.4 & 784.4 & 27.26 & 3.27 \\
\hline $\mathrm{C} 3$ & E-GDB3 & 520.8 & 594.4 & 14.13 & 1.78 \\
\hline $\mathrm{C} 5$ & E-GDB5 & 704.8 & 859.2 & 21.91 & 2.7 \\
\hline C6 & E-GDB6 & 592 & 660 & 11.49 & 1.73 \\
\hline C7 & E-GDB7 & 557.6 & 860 & 54.23 & 1.66 \\
\hline $\mathrm{C} 12$ & E-GDB12 & 786.4 & 891.2 & 13.33 & 0.7 \\
\hline $\mathrm{C} 14$ & E-GDB14 & 201.6 & 226 & 12.1 & 3.17 \\
\hline $\mathrm{C} 15$ & E-GDB15 & 112.8 & 122.4 & 8.51 & 4.11 \\
\hline $\mathrm{C} 17$ & E-GDB17 & 170.4 & 179.2 & 5.16 & 7.7 \\
\hline C19 & E-GDB19 & 91.6 & 121.2 & 32.31 & 0.52 \\
\hline C34 & E-VAL2B & 386 & 486 & 25.91 & 2.89 \\
\hline C47 & E-VAL6A & 383.2 & 455.2 & 18.79 & 8.36 \\
\hline C66 & E-EGL-E1-C & 4611.2 & 5679.8 & 23.17 & 1.51 \\
\hline C72 & E-EGL-E3-C & 7541.8 & 9992.6 & 32.5 & 3.66 \\
\hline C77 & E-EGL-S1-B & 5373.4 & 7274.2 & 35.37 & 2.25 \\
\hline \multicolumn{3}{|c|}{ Average: } & & 22.41 & 3.07 \\
\hline
\end{tabular}

When inserting a new distinct chromosome $C$ into the current population $P$, we need to locate the subinterval $I$ which covers the fitness of $C$. If the fitness of $C$ is better than the recorded fitness of $I$, then the recorded fitness of $I$ is updated and $C$ is inserted into $P$. An operation (e.g., selection, crossover, or mutation) is considered successful if $C$ can be inserted into $P$ and unsuccessful otherwise.

\section{Three Variants of the HHEA}

In this paper, three different versions of HHEA are designed for comparison. Each variant shares the same overall computational flow but employs different strategies for the operations of selection, crossover, and mutation. The variants are designed to determine whether there exists a significant difference in employing one strategy over the other. The choice of strategies is summarized in Table III. Variants HHEA-1 and HHEA-2 are employed to compare the impact of strategies S1 and S2, while HHEA-2 and HHEA-3 are employed to compare the impact of strategies S3 and S4. These strategies are explained as follows.

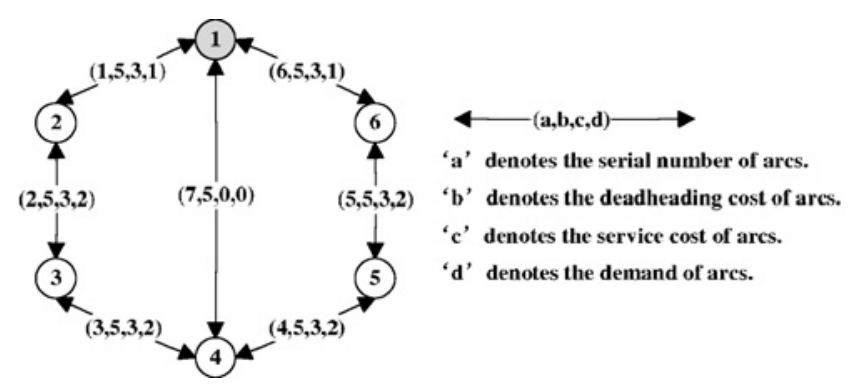

Fig. 7. Simple example of an MCARP instance. In this example, there are six nodes (node 1 is the depot node), seven arcs, and two available trucks. The capacity of trucks is six. For the sake of simplicity, the constraint of maximum service time is not considered in this example.

1) S1 (Uniform Selection of Operators): In the selection phase, rank order selection and binary tournament are chosen randomly with equal probability.

2) S2 (Empiristic Selection of Operators Using Heuristic Information): This strategy adopts the PIO to empirically select an appropriate mutation operator (see Section V-A).

3) S3 (Uniform Selection of One Broken Position): This strategy randomly selects a broken position for crossover or mutation with equal probability.

4) S4 (Empiristic Selection of the Broken Position Using Heuristic Information): In this case, AAPI is used to empirically decide one broken position (see Section V-A).

As mentioned previously, the overall computational flow, and the main and restart phase in particular, is identical across the three variants. In the main phase, selection, crossover, and mutation are the three primary operations. The main phase of HHEA is terminated when the defined number of fitness evaluations is exhausted. The partial replacement procedure is employed to maintain or increase the diversity of current population at the beginning of the restart phase. The searching process of restart phase is similar to the main phase except the different parameters.

\section{EXPERIMENTAL RESULTS}

The experiments were designed to compare HHEA-3 with ERPS, ERUH, HHEA-1, HHEA-2, and MA [10]. Each algorithm is allowed to run for 5000 fitness evaluations on each of the 107 problem instances which have up to 140 nodes and 380 arcs. Out of those instances, 87 instances are produced from existing CARP instances. As the global optima of the modified instances is unknown, the LB is obtained by MCNDLB [23] and is used as a reference value to estimate the solution quality of different approaches. Furthermore, an additional 20 instances with known optima are constructed which may be used directly to obtain the computational error of the different algorithms.

\section{A. Parameter Settings}

The HHEA was implemented using Visual $\mathrm{C}++$ language, and executed on a personal computer with the $1.8 \mathrm{GHz}$ processor and $512 \mathrm{MB}$ memory. We established a favorable choice 


\begin{tabular}{|c|c|c|c|c|}
\hline & HHEA-1 & HHEA-2 & HHEA-1 & HHEA-2 \\
\hline $\begin{array}{c}\text { MCARP } \\
\text { Instance } \\
\text { C12 }\end{array}$ & & & & \\
\hline $\begin{array}{c}\text { MCARP } \\
\text { Instance } \\
\text { C29 }\end{array}$ & & & & \\
\hline $\begin{array}{c}\text { MCARP } \\
\text { Instance } \\
\text { C55 }\end{array}$ & & & & \\
\hline $\begin{array}{c}\text { MCARP } \\
\text { Instance } \\
\text { C73 }\end{array}$ & & & & \\
\hline
\end{tabular}

Fig. 8. Performance of the different operators in HHEA-1 and HHEA-2. Symbols M1, M2, .., M6 denote the first, second, and sixth mutation operator, respectively. The symbol X1 denotes the OX operator and symbol X2 denotes the LOX operator. Ratio of selection denotes the ratio of selecting each operator throughout the whole evolution process.

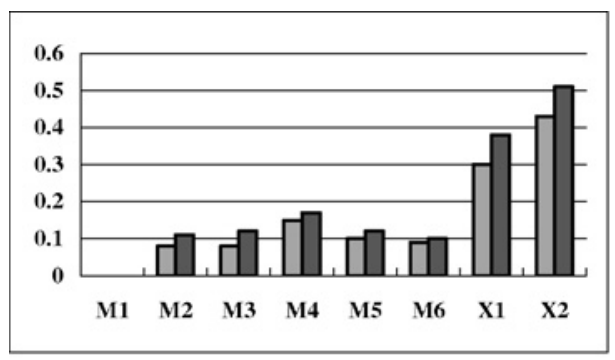

(a)

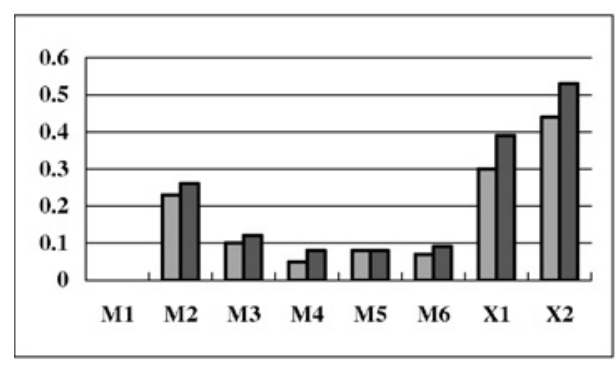

(c)

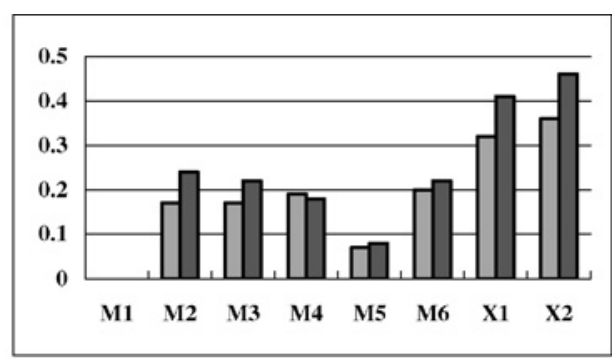

(b)

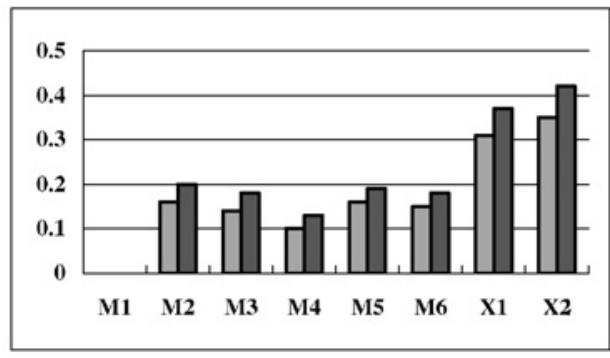

(d)

denotes the experimental results of HHEA-2 and $\square$ denotes the experimental results of HHEA-3.

Fig. 9. Performance of different operators in HHEA-2 and HHEA-3. (a) Comparative results from instance C12. (b) Comparative results from instance C29. (c) Comparative results from instance C55. (d) Comparative results from instance C73. Axis $y$ denotes the ratio of improvement and it means the probability of solution improvement by the given operator throughout the whole evolution process. Symbols M1, M2, .., M6 denote the first, second, and sixth kind of mutation operators, respectively. Symbol X1 denotes the OX operator and symbol X2 denotes the LOX operator. 
TABLE IX

EXPERIMENTAL RESUltS OF ERPS AND HHEA-3 AVERAGEd OVER 50 TRIALS (MODIFIED MCARP INSTANCES)

\begin{tabular}{|c|c|c|c|c|c|c|c|c|c|c|c|c|c|c|c|c|c|}
\hline \multirow[b]{2}{*}{ SN } & \multicolumn{4}{|c|}{ ERPS } & \multicolumn{4}{|c|}{ HHEA-3 } & & \multicolumn{4}{|c|}{ ERPS } & \multicolumn{4}{|c|}{ HHEA-3 } \\
\hline & $F_{A}$ & $F_{D}$ & $F_{4}^{E}(\%)$ & $T_{A}(\mathrm{~S})$ & $\overline{F_{A}}$ & $F_{D}$ & $F_{4}^{E}(\%)$ & $T_{A}(\mathrm{~S})$ & SN & $\overline{F_{A}}$ & $F_{D}$ & $F_{4}^{E}(\%)$ & $T_{A}(\mathrm{~S})$ & $F_{A}$ & $F_{D}$ & $F_{4}^{E}(\%)$ & $T_{A}(\mathrm{~S})$ \\
\hline $\mathrm{C} 1$ & 559 & 19.6 & 2.6 & $\begin{array}{l}69.3 \\
\end{array}$ & 562.7 & 18.8 & 3.3 & 215.2 & C45 & 867.6 & 2.8 & 11 & 78.9 & \begin{tabular}{|l|}
817.3 \\
\end{tabular} & 5 & 4.6 & 589.6 \\
\hline $\mathrm{C}^{2}$ & 633 & & & & 622 & 8. & 1. & & C46 & 1017.2 & 6.6 & 17.9 & 86 & 93 & 8.6 & & 515.3 \\
\hline C & 555.7 & 4.8 & 1.4 & 68.8 & 532 & 3.6 & 2.3 & 226 & C47 & 426.9 & 1.5 & 11.4 & 73 & 40 & 4.8 & 4. & 605.9 \\
\hline C. & 583.4 & 7.4 & 12.2 & 69 & 544.3 & 6.3 & 4 & 207.5 & C48 & 447.2 & 2 & 10.9 & 74. & 420 & 4.8 & 4.2 & 532 \\
\hline C5 & 764 & 9.2 & 8.9 & 72.1 & $\begin{array}{l}710.6 \\
500=5\end{array}$ & 9 & 0.8 & 227.9 & C49 & 527.7 & 2.9 & 17.8 & 80. & 486.3 & 4.2 & 8.5 & 328.7 \\
\hline c & $\begin{array}{l}652.4 \\
617 .\end{array}$ & 4.4 & 10.8 & 68.1 & 595. & 6.5 & 0.6 & 223 & C50 & 544.8 & 2.5 & 9.4 & 75. & 525.5 & 2 & 5.5 & 795.7 \\
\hline & $\begin{array}{l}617.3 \\
6453\end{array}$ & 5.9 & 11.2 & 68.5 & 591.5 & 6.6 & 6.1 & 211.8 & C51 & 557.3 & 3.6 & 11.9 & 77. & 527.3 & 5.7 & 5.9 & 632.2 \\
\hline C & $\begin{array}{l}645.3 \\
6287\end{array}$ & $\begin{array}{l}9.6 \\
79\end{array}$ & 32.6 & $\begin{array}{l}90.8 \\
927\end{array}$ & $\begin{array}{r}537.2 \\
611.8\end{array}$ & $\begin{array}{r}6.7 \\
13.4\end{array}$ & & $87^{\circ}$ & $\begin{array}{l}\text { C52 } \\
\text { C53 }\end{array}$ & $\begin{array}{l}643.5 \\
757.5\end{array}$ & 3. & $\begin{array}{l}20.6 \\
84\end{array}$ & 85 & $\begin{array}{l}60 \\
73\end{array}$ & 7.1 & & 409.1 \\
\hline C10 & 564.2 & 4.3 & 7.4 & 68.2 & 535.9 & $\begin{array}{l}13.4 \\
4.4\end{array}$ & 1.3 & 2413 & C54 & $\begin{array}{l}113.9 \\
7896\end{array}$ & $\begin{array}{l}9.4 \\
6.4\end{array}$ & $\begin{array}{l}8.4 \\
13\end{array}$ & 76. & $\begin{array}{l}758.0 \\
\mathbf{7 4 8 . 9}\end{array}$ & $\begin{array}{l}4.2 \\
5.4\end{array}$ & 72 & $\begin{array}{l}1248.1 \\
952.5\end{array}$ \\
\hline & 795.3 & 6.2 & 11.1 & 72.4 & 751.3 & 4.3 & 4.6 & 335.8 & C55 & 945 & 9. & 26.2 & 84. & 854.8 & 20.1 & 14.2 & 541.4 \\
\hline & 908.3 & 7.3 & 16.0 & 70.7 & 815. & 5.1 & 3.7 & 219.1 & C5 & 615 & 1.4 & 6.8 & 80 & & 5.2 & 1.8 & 2911.2 \\
\hline C13 & 1059.4 & 48.1 & 2.3 & 60.1 & 1053.9 & 24.1 & $\begin{array}{l}1.8 \\
1.8\end{array}$ & 220 & C57 & $\begin{array}{l}624.4 \\
62.2\end{array}$ & $\begin{array}{l}1.4 \\
3.5\end{array}$ & $\begin{array}{l}0.0 \\
10.7\end{array}$ & 83 & 596 & 3.7 & $\begin{array}{l}1.0 \\
5.8\end{array}$ & 2064.9 \\
\hline C14 & 212.3 & 1.2 & 5.3 & 67.2 & 205.7 & 1.1 & 2 & 199.3 & C58 & 642.8 & 3.3 & 11.9 & 84. & 603.8 & 4.1 & 5.1 & 1683.6 \\
\hline C15 & 117 & 1.1 & 3.7 & 69.2 & 113.8 & 0.3 & 0.9 & 211.4 & C59 & 736.2 & 8.5 & 18.2 & 96. & 649.4 & 4.7 & 4.3 & 950.3 \\
\hline C16 & 251.6 & 1.2 & 4.3 & 68.8 & 249.9 & 1.2 & 3.6 & 227.7 & C60 & 802.8 & 5.3 & 6.3 & 84. & 789.1 & 5.9 & 4.5 & 1809.1 \\
\hline C17 & 174.5 & 1 & 2.4 & 68.8 & 170.8 & 0.5 & 0.2 & 227 & C61 & 818.2 & 2.5 & 6.1 & 86.1 & 796 & 2.6 & 3.2 & 1385.4 \\
\hline $\mathrm{C}$ & 346.4 & 1.4 & 6.4 & 70 & 332.6 & 2.4 & 2.1 & 282.2 & C62 & 854.6 & 2.6 & 6.5 & 89.8 & 819.9 & 4.4 & 2.2 & 1349.5 \\
\hline C & 93.5 & 1.6 & 2.1 & 64.2 & 92.6 & 1.4 & 1.1 & 167.2 & C63 & 914.6 & 5.1 & 12.3 & 99.6 & 864.7 & 4.1 & 6.2 & 775.2 \\
\hline C & 237.7 & 2.1 & 6.7 & 69.2 & 233.1 & 2.9 & 4.6 & 215.9 & C64 & 4615.8 & 25.8 & 36.7 & 86 & 4237.6 & 41.6 & 25.5 & 522.3 \\
\hline C & 322 & 1 & 2.8 & 70.5 & 315. & 3.1 & 0.6 & 226.2 & C65 & 5249.8 & 66.4 & 41.1 & 90.5 & 4733 & 61.5 & 27.2 & 538.8 \\
\hline & 400.6 & 1 & 2.3 & & 396 & 2.8 & 1.1 & 283.1 & C66 & 6086.8 & 57.5 & 32 & 97 & & 69.6 & 18.4 & 491.6 \\
\hline C23 & $\begin{array}{l}472.2 \\
15.6\end{array}$ & 1.2 & 3.2 & 78.6 & 470.4 & 2.1 & 2.8 & 334 & C67 & 5943.8 & 64.5 & 36.4 & 98.4 & 5491.6 & 33.8 & 26 & 688.5 \\
\hline C24 & $\begin{array}{l}21566 \\
0\end{array}$ & 189.1 & 7.8 & 66.2 & 20943 & 102.5 & 4.7 & 199.3 & C68 & 7733.5 & 63.8 & 33.9 & 109.6 & 6884.1 & 115.4 & 19.2 & 731.4 \\
\hline C & $\begin{array}{l}15763 \\
17616\end{array}$ & 373.4 & 7.9 & $\begin{array}{l}66 \\
654\end{array}$ & 15027 & 92.8 & 2.9 & 193.8 & $\begin{array}{l}\text { C69 } \\
\end{array}$ & $\begin{array}{l}7882.9 \\
68010\end{array}$ & 35.7 & 46.8 & 114.9 & & 220.2 & 39.7 & 565.1 \\
\hline & 1761 & $\begin{array}{l}100.3 \\
3781\end{array}$ & 7 & 65.4 & $\begin{array}{l}17016 \\
10925\end{array}$ & $\begin{array}{l}173.5 \\
2170\end{array}$ & 3.4 & $\begin{array}{l}194.6 \\
1965\end{array}$ & C7 & $\begin{array}{l}6891.9 \\
02084\end{array}$ & 99.9 & 30.1 & 106 & & $\begin{array}{l}185.7 \\
007 .\end{array}$ & 27.7 & 859.1 \\
\hline $\mathrm{C}^{2}$ & $\begin{array}{l}21517 \\
23447\end{array}$ & $\begin{array}{l}378.1 \\
284.6\end{array}$ & $\begin{array}{l}21.1 \\
15.3\end{array}$ & $\begin{array}{c}66 \\
65.8\end{array}$ & $\begin{array}{l}19925 \\
22849\end{array}$ & $\begin{array}{l}211.9 \\
552.8\end{array}$ & 12.1 & $\begin{array}{l}196.5 \\
2037\end{array}$ & C & 9208.4 & $\begin{array}{l}46 \\
60\end{array}$ & $\begin{array}{l}27.3 \\
46.5\end{array}$ & 12 & & $\begin{array}{l}297.8 \\
96.3\end{array}$ & 21 & $\begin{array}{l}940.4 \\
8027\end{array}$ \\
\hline $\mathrm{C}^{2}$ & 23061 & 128.2 & 13.1 & 6 & 22380 & 110.2 & 9.8 & 200.6 & $\mathrm{C}$ & 7737.5 & 70.2 & $\begin{array}{l}40 \\
46\end{array}$ & 10 & 3 & 396 & 31.7 & $\begin{array}{l}002.1 \\
1862.8\end{array}$ \\
\hline C. & 316.5 & 1.2 & 7.5 & & 304.5 & $2.8^{2}$ & 3.4 & 536.4 & C 7 & 9526.4 & 79.4 & $\begin{array}{l}62.4 \\
6.0\end{array}$ & & 8 & $\begin{array}{l}188.3 \\
\end{array}$ & 43.6 & $\begin{array}{l}1289.1 \\
128.1\end{array}$ \\
\hline C: & 328.6 & 1.5 & 11.6 & & 32 & 4.3 & 11.5 & 465.2 & C & 12319 & 125.1 & 98.4 & 15 & 2 & 328.1 & 58.4 & 1391 \\
\hline $\mathrm{C}$ & 415.7 & 3.1 & 20 & 7. & 38 & 8.3 & 11.5 & 311.1 & $\mathrm{C}$ & 607 & 89 & 28.8 & 12 & 54 & 43.4 & 15.8 & $\begin{array}{l}1058.9 \\
\end{array}$ \\
\hline $\mathrm{C}$ & 398.8 & 5.1 & 4.4 & & 39 & 3 & 2.2 & 423.4 & C77 & 779 & 90.1 & 45.1 & 14 & 6551.1 & $\begin{array}{l}710.9 \\
\end{array}$ & 21.9 & 981.3 \\
\hline $\mathrm{C}$ & 423.4 & 5.9 & 9.7 & & 39 & 3.5 & 3 & 34 & C78 & & 124.8 & 32.3 & 16 & 923 & 190.2 & 26.1 & 1010.4 \\
\hline & & 5.5 & 22.3 & & & 5.4 & 21.4 & & C & 127 & 118.9 & 47.2 & & & 780.3 & 30.7 & 2912.3 \\
\hline C. & & 1.2 & 6 & & 13 & 0.4 & 2.6 & 43 & C & 15334 & 103.4 & 49 & 24 & 14 & 248.9 & 37.5 & 2048.6 \\
\hline C & & 1 & 7.8 & & 135.4 & 0.8 & 2.9 & 332 & C & 173 & 78.8 & 62.4 & & 15 & 314.7 & 42.8 & 1995.9 \\
\hline C. & 17 & 1.8 & 22.5 & & 174.9 & 3.6 & 20.5 & 257.2 & C & 129 & 64.7 & 50.4 & & & 78.6 & 20.3 & 2897.2 \\
\hline C. & 737.8 & 4.6 & 6. & & 7 & 3.9 & 5 & 9 & C\& & 19 & 165.5 & 82 & 34 & & 302.9 & 28.7 & 2656.9 \\
\hline $\mathrm{C}$ & 770 & 4.8 & 7.8 & 78 & 737.3 & 2.6 & 3.2 & 75 & C84 & 18897 & 150.5 & 53.9 & & 17 & 332.5 & 39.1 & 2499 \\
\hline C41 & 815 & 4.9 & 10.8 & 83 & 775.6 & 6.1 & 5.4 & 62 & C85 & 16627 & 249.6 & 65.1 & 322.1 & 12759 & 869.3 & 26.7 & 2818.4 \\
\hline C4 & 898.1 & 5.9 & 14.5 & 87.5 & 822.5 & 3.8 & 4.9 & & C8 & 18311 & 122.4 & 69 & & 15052 & 269.3 & 38.9 & 2044 \\
\hline $\begin{array}{l}\text { C43 } \\
\text { C44 }\end{array}$ & $\begin{array}{r}x \\
795.4\end{array}$ & $\begin{array}{c}x \\
6.4\end{array}$ & $\begin{array}{c}x \\
7.2\end{array}$ & $\begin{array}{l}x \\
77\end{array}$ & $\begin{array}{l}777.2 \\
767.7\end{array}$ & 8.1 & $\begin{array}{l}4.7 \\
3.5\end{array}$ & $\begin{array}{l}810.8 \\
6397\end{array}$ & C87 & 25278 & 226.7 & 89.7 & 420.1 & 18467 & 188.6 & 38.6 & 2166.3 \\
\hline
\end{tabular}

Symbol " $\times$ " indicates that no feasible solution can be obtained adopting the given approach. Values in bold face indicate that the performance of HHEA-3 is significantly better than that of ERPS (the confidence degree is 0.95 ) on the given instance.

of parameters, as listed in Table IV, by means of systematic experimentation. The Wilcoxon signed ranks test [57] is employed for the comparison of the different approaches. In this paper, the final experimental results were averaged over 50 trials. A summary of abbreviations used is given in Table V.

\section{B. Modified MCARP Instances}

A total of 87 modified MCARP instances were generated based on four sets of benchmark files [58] which may be downloaded from http://www.uv.es/ belengue/carp.html. Experimental results suggest that the conversion from CARP to MCARP is very quick and each CARP instance can be converted to a MCARP instance within a fraction of a second. The modified instances can be downloaded from http://xinglining.googlepages.com/home. The attributes of the modified MCARP instances are summarized in Table VI and the attributes of the underlying CARP instances are as follows.

1) GDB: 23 undirected CARP instances which were randomly constructed by Golden et al. [26]. These instances have 7-27 nodes and 11-55 edges and are denoted by gdb1, gdb2, .., gdb23. In each instance of this set, all edges are required.

2) KSHS: Six standard CARP instances which were randomly generated by Kiuchi et al. [59]. All edges are required in each instance of this set. The instances (denoted by kshs 1 to kshs6) have 6-10 nodes and 15 edges.
3) BCCM: 34 undirected CARP instances which were randomly generated by Benavent et al. [60] based on 10 different graphs. For each graph, some instances were generated (denoted *.A, *.B, ...) by changing the capacity of vehicles. In each instance of this set, all edges are required. The instances have 24-50 nodes and 34-97 edges.

4) EGLESE: 24 undirected instances constructed from real data by $\mathrm{Li}$ and Eglese [61]. These instances are very interesting because of their large size and real-world relevance. The data used to generate the instances represent road networks of two areas (east and south) of the county of Lancashire, U.K., which were digitized for the research of winter gritting. These EGLESE instances have sizes considerably greater than those in the preceding sets: 77-140 nodes, 98-190 edges, and up to 35 vehicles; also, many instances include nonrequired edges.

\section{MCARP Instances with Known Optima}

In order to further evaluate the HHEA framework, 20 MCARP instances were designed from scratch (these instances can be downloaded from http://xinglining.googlepages.com/ home). The optima of these instances are known, and hence they can be applied directly to estimate the computational error of the different algorithms. Also, the gap between $F_{A}$ and $F^{*}$ (see Table $\mathrm{V}$ for an explanation of symbols), the gap 
TABLE X

EXPERIMENTAL RESUltS OF HHEA-1 AND HHEA-2 AVERAGED OVER 50 TRIALS FOR THE MODIFIED MCARP INSTANCES

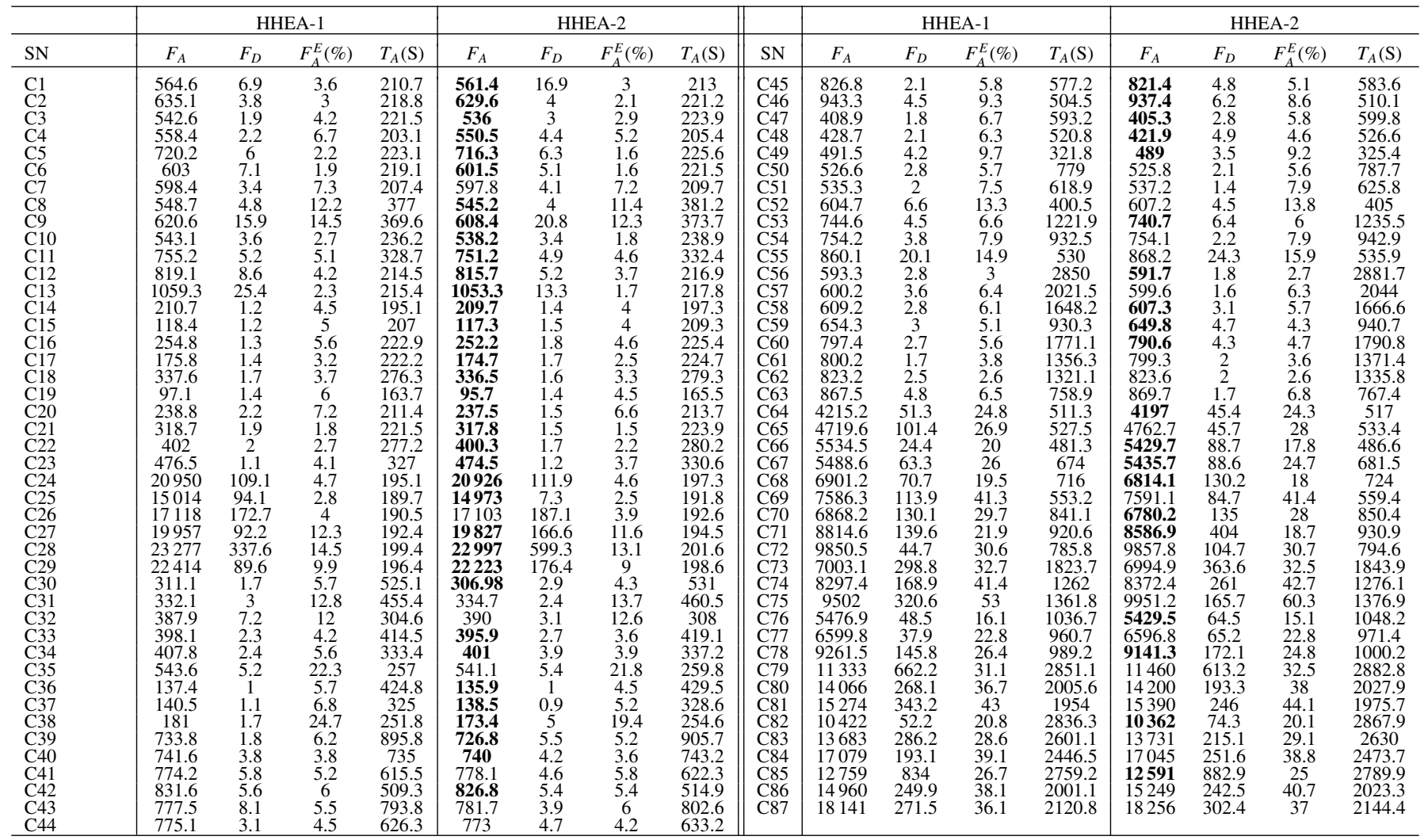

Values in bold face indicate that the performance of HHEA-2 is significantly better than that of HHEA-1 (the confidence degree is 0.95 ).

between $F^{*}$ and $L_{b}$, and the gap between $F_{A}$ and $L_{b}$ can be computed directly. The relationship between these gaps can then be further analyzed. The attributes of these MCARP instances are summarized in Table VII.

\section{Experimental Results of EAM Heuristic}

As mentioned before, the EAM heuristic is a deterministic approach and always obtains the same solution every time it is executed on the same instance. EAM can only find feasible solutions for 15 out of all modified MCARP instances as summarized in Table VIII. The average computational error of EAM is about $22 \%$ and the average computational time is about three seconds. Subsequently, EAM was not employed for further comparison because of its poor performance.

\section{E. Comparison of ERPS and HHEA-3}

Experimental results of ERPS and HHEA-3 are summarized in Table IX. Experimental results suggest that the performance of HHEA-3 is significantly better than that of ERPS. As mentioned before, ERPS was applied to generate some initial individuals in the main phase and restart phase of the HHEA-3. HHEA-3, however, then evolves these individuals into solutions that are at least as good as the initial ones. For this reason, HHEA-3 should be more powerful than ERPS and this was demonstrated by the final experimental results. For example, given the MCARP instance shown in Fig. 7, the total cost of optimal solutions is 58 and its optimal solution is as follows.
1) Tour 1: 1, 2, 3, 7 (arcs 1, 2, and 3 were serviced).

2) Tour 2: 6, 5, 4, 7 (arcs 6, 5, and 4 were serviced).

ERPS appends the most promising arc to the sequence of arcs until $Q$ or $T$ is exhausted. One optimal solution gained by ERPS (total cost is 68) is as follows.

1) Tour 1: 1, 2, 3, 4, 5, 6 (arcs 1, 2, 3, and 6 were serviced).

2) Tour 2: 6, 5, 4, 7 ( $\operatorname{arcs} 5$ and 4 were serviced).

ERPS is a stochastic algorithm with rather simple rules, and hence the greediness of its working mechanism results in inferior solutions. Different to ERPS, HHEA-3 generates the initial individuals using ERPS and ERUH, and improves the solution quality through crossover and mutation. The solution obtained by ERPS can be converted into a chromosome $(1,2,3,6,5,4)$. After obtaining its fitness by the split procedure, the actual optimal solution will be reached. In summary, ERPS cannot obtain high-quality solutions because of the greediness of its working mechanism, but this disadvantage can be overcome by HHEA through the fitness evaluations, crossover, and mutation.

\section{F. Comparison of ERUH and HHEA-3}

The experimental results of ERUH and HHEA-3 are listed in Table XI. The final results suggest that the performance of HHEA-3 is significantly better than that of ERUH. ERUH is a stochastic algorithm with simple rules but it can produce fairly good MCARP solutions. As mentioned previously, ERUH was used to generate some initial solutions in the main and 
TABLE XII

EXPERIMENTAl RESUlts OF HHEA-2 AND HHEA-3 AVERAgEd Over 50 TRIAls FOR SOlving Modified MCARP INSTANCES

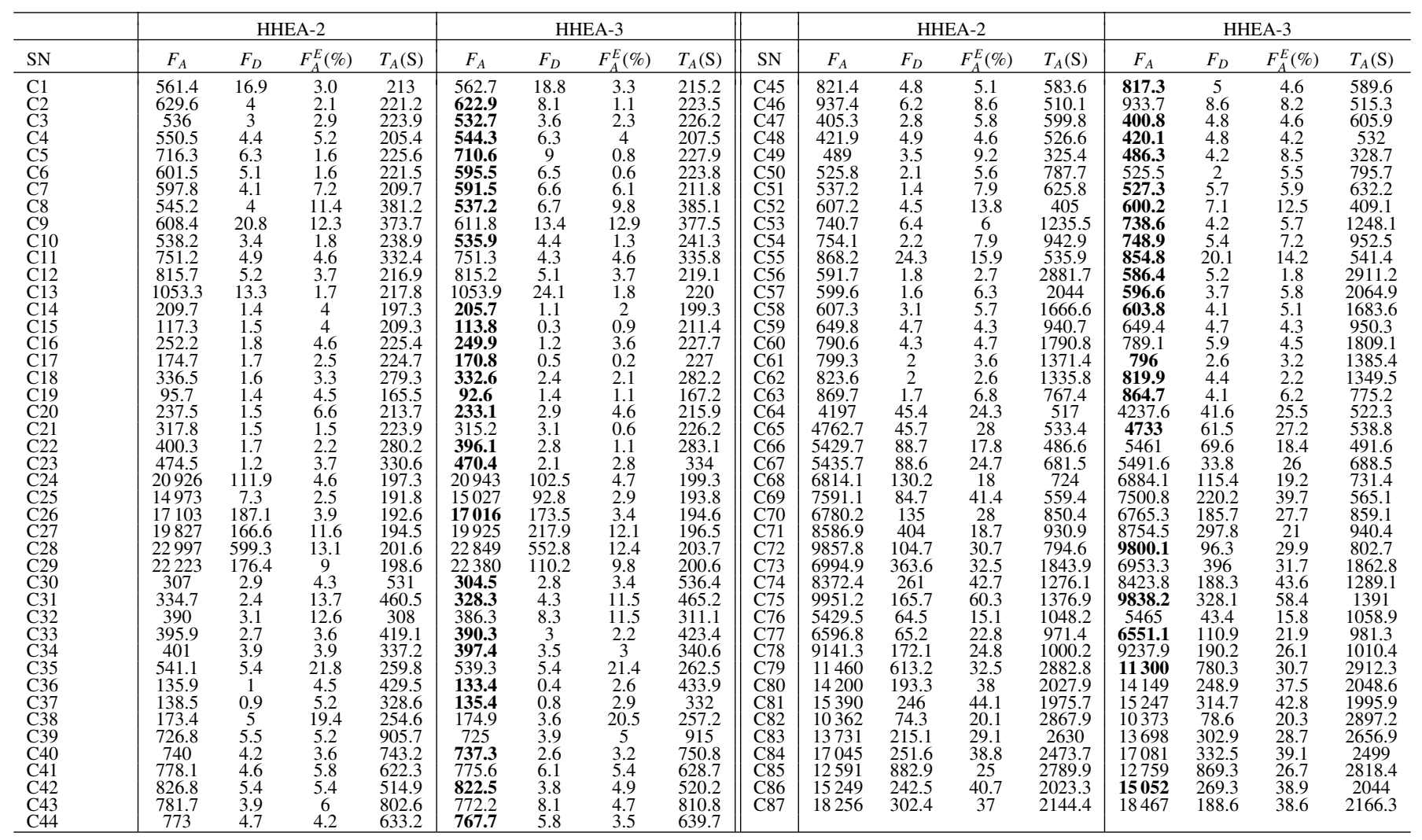

Values in bold face indicate that the performance of HHEA-3 is significantly better than that of HHEA-2 (the confidence degree is 0.95 ).

TABLE XIII

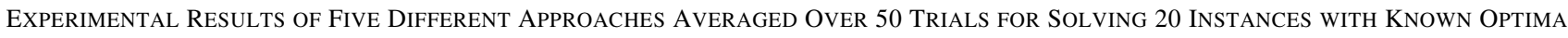

\begin{tabular}{|c|c|c|c|c|c|c|c|c|c|c|c|c|c|c|c|c|c|c|c|c|}
\hline \multirow[b]{2}{*}{ SN } & \multicolumn{4}{|c|}{ ERPS } & \multicolumn{4}{|c|}{ ERUH } & \multicolumn{4}{|c|}{ HHEA-1 } & \multicolumn{4}{|c|}{ HHEA-2 } & \multicolumn{4}{|c|}{ HHEA-3 } \\
\hline & $F_{A}$ & $F_{A}^{E}(\%)$ & $F_{A}^{*}(\%)$ & $T_{A}(\mathrm{~S})$ & $F_{A}$ & $F_{A}^{E}(\%)$ & $F_{A}^{*}(\%)$ & $T_{A}(\mathrm{~S})$ & $F_{A}$ & $F_{A}^{E}(\%)$ & $F_{A}^{*}(\%)$ & $T_{A}(\mathrm{~S})$ & $F_{A}$ & $F_{A}^{E}(\%)$ & $F_{A}^{*}(\%)$ & $T_{A}(\mathrm{~S})$ & $F_{A}$ & $F_{A}^{E}(\%)$ & $F_{A}^{*}(\%)$ & $T_{A}(\mathrm{~S})$ \\
\hline $\mathrm{E} 02$ & 322 & 47.7 & 22.9 & 89.62 & 270 & 23.9 & 3.1 & 222.14 & 270 & 239 & 3.1 & 178.02 & 266.8 & 22.4 & 1.8 & 179.63 & 262 & 20.2 & 0.0 & 178.84 \\
\hline E03 & 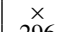 & 258 & 120 & 67 & $x^{x}$ & 23 & 3 & רכ & 254 & 46.0 & 21.0 & 250.85 & 235.6 & 35.4 & 12.2 & 275.31 & 226 & 29.9 & 7.6 & 268.45 \\
\hline E06 & 396 & 33.8 & 22.2 & 82.53 & 350 & 18.2 & 8.0 & 195.49 & 350 & 18.2 & 8.0 & 154.39 & 348 & 17.6 & 7.4 & 153.12 & 342 & 15.5 & 5.6 & 153.57 \\
\hline E07 & & & & & 292 & 30.4 & 7.4 & 231.41 & 292 & 30.4 & 7.4 & 176.37 & 283.6 & 26 & 4.3 & 174.16 & 280 & 25.0 & 2.9 & 173.17 \\
\hline E & 388 & 31.1 & 19.8 & 69.19 & 350 & 18.2 & 8.0 & 193.56 & 350 & 18. & 8.0 & 149.6 & 347.2 & 17 & 7.2 & 153.2 & 340 & 14.9 & 4.9 & 154.81 \\
\hline $\mathrm{E}$ & 488 & 48.8 & 35.6 & 74.09 & 400 & 22.0 & 11.1 & 435.72 & 400 & 22 & 11.1 & 348.5 & 396.8 & 21 & 10.2 & 344.27 & 398 & 21. & 10.6 & 347.01 \\
\hline $\mathrm{F}$ & 585 & 38.0 & 18.9 & 82.46 & 530 & 25.0 & 7.7 & 318.98 & 530 & 25 & 7.7 & 260.52 & 526 & 24 & 6.9 & 254.74 & 520 & 22 & 5.7 & 254.19 \\
\hline $\mathrm{E}$ & 815.2 & 46.6 & 22.0 & 85.57 & 707.6 & 27.3 & 5.9 & 515.88 & 716 & 28 & 7.2 & 430.35 & 709.4 & 27 & 6.2 & 416.22 & 702 & 26 & 5.1 & 416.59 \\
\hline $\mathrm{E}$ & $\times$ & $\times$ & $\times$ & . & 612 & 31.9 & 15.0 & 737.56 & 596 & 28 & 12.0 & 644.15 & 581.6 & 25 & 9. & 616.22 & 568 & 22 & 6.8 & 621.1 \\
\hline $\mathrm{E}$ & 820 & 47.5 & 22.8 & 83.7 & 707.6 & 27.3 & 5.9 & 516.18 & 718 & 29 & 7.5 & 416.95 & 710.6 & 27 & 6. & 413.95 & 700 & 25 & 4.8 & 418.05 \\
\hline $\mathrm{E}$ & $x$ & $x$ & $x$ & $x$ & 584 & 20.7 & 8.1 & 1039.28 & 580 & 19 & 7.4 & 904.35 & 569 & 17 & 5 & 87 & 562 & 16 & 4.1 & 882.18 \\
\hline $\mathrm{E}$ & 945 & 50.0 & 25.3 & 539.52 & 796.2 & 26.4 & 5.6 & 693.83 & 806 & 27 & 6.9 & 612.5 & 793.8 & 26 & 5 & 61 & 6 & 24 & 4.2 & 616.84 \\
\hline E1s & $\times$ & $\times$ & $x$ & 163.13 & 610 & 18.7 & 10.9 & 1033.41 & 606 & 17.9 & 10.2 & 858.56 & 587.6 & 14. & 6. & 865.33 & 582 & 13.2 & 5.8 & 845.31 \\
\hline E20 & 924.6 & 46.8 & 22.6 & 532.34 & 798 & 26.7 & 5.8 & 698.31 & 804 & 27.6 & 6.6 & 611.94 & 789.6 & 25.3 & 4.7 & 620.68 & 788 & 25.1 & 4.5 & 616.14 \\
\hline & & 42.5 & 23.7 & & & 24.4 & 8.4 & & & 25.1 & 8.7 & & & 23.0 & 6.9 & & & 21.2 & 5.3 & \\
\hline
\end{tabular}

Symbol " $\times$ " indicates that none of the feasible solutions can be obtained by the given approach. 


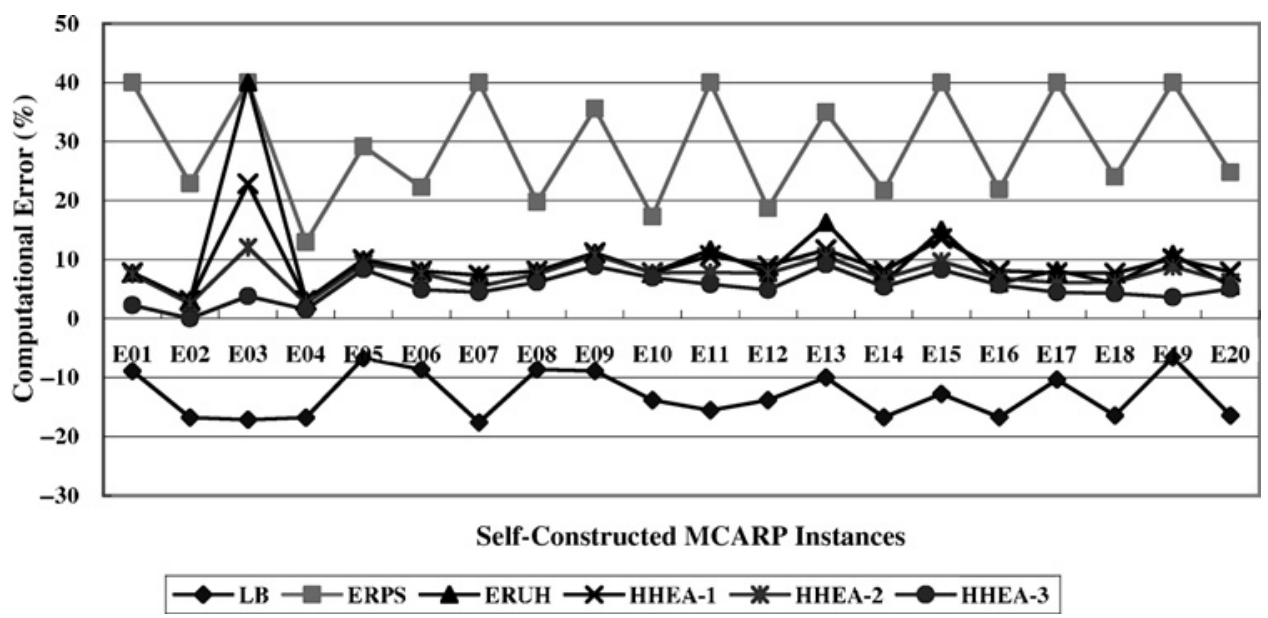

Fig. 11. Relationship between $F_{A}, F^{*}$, and $L_{b}$. For each instance with known optimum, $F^{*}$ is regarded as the datum mark $\left(x\right.$-axis), $F_{A}$ is located above the datum mark, and $L_{b}$ is located under the datum mark. In this figure, both $F_{A}$ and $L_{b}$ adopt the corresponding gap to the $F^{*}$. Above the datum mark, if the gap is reached to $40 \%$, then it means that it cannot obtain a feasible solution of this instance by the given approach.

TABLE XIV

FinAl Results of MA AND HHEA-3 AVERAged OVER 50 TRIALS FOR SOLVING 23 SIMPLE MCARP INSTANCES

\begin{tabular}{l|cccc|cccc}
\hline & \multicolumn{5}{|c|}{ MA } & \multicolumn{4}{c}{ HHEA-3 } \\
\hline SN & $F_{A}$ & $F_{D}$ & $F_{A}^{E}(\%)$ & $T_{A}(\mathrm{~S})$ & $F_{A}$ & $F_{D}$ & $F_{A}^{E}(\%)$ & $T_{A}(\mathrm{~S})$ \\
\hline C1 & 573.7 & 23.5 & 5.3 & 191.3 & $\mathbf{5 6 2 . 7}$ & 18.8 & 3.3 & 215.2 \\
C2 & 636.1 & 14.8 & 3.2 & 195.6 & $\mathbf{6 2 2 . 9}$ & 8.1 & 1.1 & 223.5 \\
C3 & 535.9 & 6.9 & 2.9 & 189.3 & $\mathbf{5 3 2 . 7}$ & 3.6 & 2.3 & 226.2 \\
C4 & 561.9 & 10.2 & 7.4 & 178.6 & $\mathbf{5 4 4 . 3}$ & 6.3 & 4 & 207.5 \\
C5 & 734.4 & 11.7 & 4.2 & 188.7 & $\mathbf{7 1 0 . 6}$ & 9 & 0.8 & 227.9 \\
C6 & 614.5 & 9.8 & 3.8 & 181.5 & $\mathbf{5 9 5 . 5}$ & 6.5 & 0.6 & 223.8 \\
C7 & 603.9 & 11.3 & 8.3 & 187.9 & $\mathbf{5 9 1 . 5}$ & 6.6 & 6.1 & 211.8 \\
C8 & 552.3 & 10.2 & 12.9 & 290.4 & $\mathbf{5 3 7 . 2}$ & 6.7 & 9.8 & 385.1 \\
C9 & 612.5 & 15.9 & 13 & 285.3 & $\mathbf{6 1 1 . 8}$ & 13.4 & 12.9 & 377.5 \\
C10 & 541 & 6.7 & 2.3 & 217.3 & $\mathbf{5 3 5 . 9}$ & 4.4 & 1.3 & 241.3 \\
C11 & 752.2 & 6.9 & 4.7 & 273.4 & $\mathbf{7 5 1 . 3}$ & 4.3 & 4.6 & 335.8 \\
C12 & 824.9 & 8.4 & 4.9 & 185.9 & $\mathbf{8 1 5 . 2}$ & 5.1 & 3.7 & 219.1 \\
C13 & 1052.2 & 30.8 & 1.6 & 181.4 & 1053.9 & 24.1 & 1.8 & 220 \\
C14 & 207 & 3.5 & 2.7 & 185.1 & $\mathbf{2 0 5 . 7}$ & 1.1 & 2 & 199.3 \\
C15 & 114.9 & 1.2 & 1.9 & 183.6 & $\mathbf{1 1 3 3 . 8}$ & 0.3 & 0.9 & 21.4 \\
C16 & 250.6 & 1.9 & 3.9 & 203.8 & $\mathbf{2 4 9 . 9}$ & 1.2 & 3.6 & 227.7 \\
C17 & 172.3 & 1.2 & 1.1 & 199.6 & $\mathbf{1 7 0 . 8}$ & 0.5 & 0.2 & 227 \\
C18 & 339 & 3.1 & 4.1 & 228.7 & $\mathbf{3 3 2 . 6}$ & 2.4 & 2.1 & 282.2 \\
C19 & 92.8 & 1.4 & 1.3 & 168.2 & 92.6 & 1.4 & 1.1 & 167.2 \\
C20 & 243.1 & 3.7 & 9.1 & 190.3 & $\mathbf{2 3 3 . 1}$ & 2.9 & 4.6 & 215.9 \\
C21 & 318.5 & 3.8 & 1.7 & 213.5 & $\mathbf{3 1 5 . 2}$ & 3.1 & 0.6 & 226.2 \\
C22 & 399 & 4.9 & 1.9 & 219.8 & $\mathbf{3 9 6 . 1}$ & 2.8 & 1.1 & 283.1 \\
C23 & 474.5 & 3.5 & 3.7 & 320.3 & $\mathbf{4 7 0 . 4}$ & 2.1 & 2.8 & 334 \\
\hline
\end{tabular}

Values in bold face indicate that the performance of HHEA-3 is significantly better than that of MA (the confidence degree is 0.95 ).

HHEA-2 uses strategy S3 which selects a broken position with the equal probability, while HHEA-3 makes use of strategy S4 which selects a broken position using the AAPI information. It follows that the probability of solution improvement by each operator in HHEA-3 should be higher than that in HHEA-2 and this is indeed the case as shown in Fig. 9. HHEA-3 selects a favorable broken position for each crossover (mutation) operation employing the AAPI information and thereby protecting promising subsequences in the current chromosome. The probability of solution improvement by each operator is thus largely improved. For example, executing HHEA-2 on instance C55, about $30 \%$ of crossovers of all crossovers executed by OX result in an improved solution, and about $44 \%$ of crossovers of all crossovers executed using LOX obtain an improved solution. Comparatively, among the whole evolutionary processes of HHEA-3, about $39 \%$ of OX crossovers and $53 \%$ of LOX crossovers result in an improved solution.

\section{Comparison of MA and HHEA-3}

In this section, 23 simple MCARP instances (C1-C23) were used to compare the performance of MA [10] and HHEA-3. As we consider a maximum service time, MA cannot be directly applied to deal with MCARP instances. Therefore, the split procedure in MA is replaced by the extended split procedure. Final experimental results of MA and HHEA-3 are listed in Table XIV. Experimental results suggest that the performance of HHEA-3 is significantly better than that of MA. In MA, most initial individuals are produced using random generation. In fact, the quality of the initial population will largely affect the final performance of optimization methods. In HHEA, most initial individuals are generated using ERPS and ERUH and PIO is used to select the appropriate operator for selection, crossover, and mutation and AAPI is applied to decide the appropriate broken position for crossover and mutation. For this reason, HHEA-3 should be more powerful than MA and it was demonstrated by the final results.

\section{J. Experimental Results of Instances with Known Optima}

The computational error of each optimization methods should be estimated by the gap $F_{A}^{*}$ between $F_{A}$ and $F^{*}$. Unfortunately, $F^{*}$ is unknown for the modified MCARP instances and the computational error is, therefore, replaced by the gap $F_{A}^{E}$ between $F_{A}$ and $L_{b}$. However, there still exists a gap between $F^{*}$ and $L_{b}$ (i.e., $L_{b}$ is not necessarily tight) and in order to completely understand the relationship between $F_{A}^{E}$ and $F_{A}^{*}$, some experiments were implemented on the MCARP instances where $F^{*}$ is known. The Three HHEA variants as well as the two extended heuristics (ERPS and ERUH) were used to solve these instances and the results are shown in Table XIII. As displayed in Fig. 10, there exists a large gap between $F_{A}^{E}$ and $F_{A}^{*}$. For example, the error $F_{A}^{E}$ of HHEA-3 is $21.2 \%$, whereas the error $F_{A}^{*}$ of HHEA-3 is $5.3 \%$. Given the error $F_{A}^{E}$ of HHEA-3, the actual error $F_{A}^{*}$ is $5.3 \%$ (about $25 \%$ ) and the additional error is $15.9 \%$ (about $75 \%$ ). In summary, there is a gap between $L_{b}$ and $F^{*}$ and this gap (44-75\%; Fig. 10) makes error $F_{A}^{E}$ larger than error $F_{A}^{*}$. 


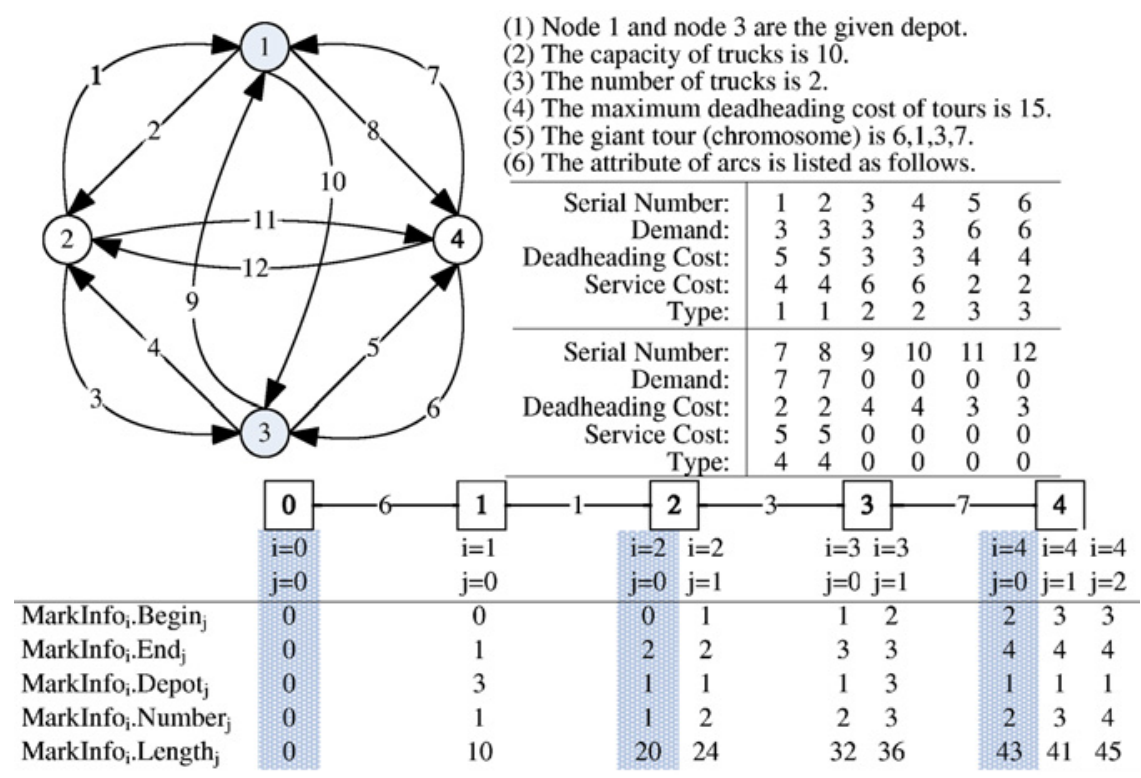

Fig. 12. Simple example of the proposed multimark approach. After the operation, there are three different marks on virtual node 4 . In fact, the best tradeoff is the leftmost one (total cost is 43 , while the number of trucks is 2 ).

Fig. 11 highlights the relationship between $L_{b}, F^{*}$, and $F_{A}$. From this figure, the following conclusions may be reached: First, there exists a large gap between $L_{b}$ and $F^{*}$. Among these 20 instances, the average gap between $L_{b}$ and $F^{*}$ is $12.97 \%$ (the smallest is $6.7 \%$, the largest is $16.8 \%$ ). Second, the $F_{A}$ obtained by HHEA-3 is very close to $F^{*}$. Among these 20 instances, the average gap between $F_{A}$ and $F^{*}$ is $5.19 \%$ (the smallest is 0 and the largest is $9.2 \%$ ).

\section{CONCLUSION}

This paper has proposed a novel EA called HHEA that employs classical heuristics as well as heuristic information to deal with the MCARP, an extension of the classical CARP. The experimental results demonstrate that HHEA significantly outperforms other heuristics. The main contributions of this paper may be summarized as follows: considering practical requirements, the MCARP was introduced. Both multidepots and maximum service time were taken into account to guarantee the availability of timely service. This paper is a step closer toward a more practical version of CARP problems. Also, three classical heuristics were extended to the MCARP and two of those, ERPS and ERUH, were used to initialize the population of HHEA. Furthermore, heuristic information was used to guide the evolutionary search of HHEA. As mentioned above, the initial individuals were generated using ERPS and ERUH. This not only improves the quality of the initial population but also ensures that feasible solutions are available. Furthermore, heuristic information was extracted from near-optimal solutions that are acquired throughout the search. This information was subsequently used to guide the subsequent evolution. In particular, the PIO was employed to select appropriate selection, crossover, and mutation operators and the AAPI was used to decide favorable positions for crossover and mutation.

There are many aspects that we intend to address in the near future. In particular, we would like to construct an improved approach for estimating the LB of MCARP instances. In this paper, the MCNDLB [23] was employed to estimate the LBs of MCARP instances. As mentioned before, the average gap between $L_{b}$ and $F^{*}$ is $12.97 \%$ among the 20 instances with known global optimum. Therefore, an improved algorithm should be developed for estimating the LB of MCARP instances.

\section{ACKNOWLEDGMENT}

The authors would like to thank all the members of the Evolutionary Algorithms for Dynamic Optimization Problems reading group (CERCIA) for their valued suggestions. In particular, they would like to thank T. T. Nguyen, Dr. H. Handa, and Dr. T. Ray for their constructive comments and suggestions. They are also grateful to the CERCIA group at the School of Computer Science, University of Birmingham, for providing a working environment and experimental facilities.

\section{APPENDIX A \\ ADDITIONAL MCARP CONCEPTS}

Additional MCARP concepts are listed as follows.

1) Mixed Connected Graph: The mixed graph allows for two kinds of links - undirected edges and directed arcs. In this paper, a mixed connected graph is transformed into a directed connected graph by replacing each edge by two arcs with opposing directions.

2) Type of Arcs: Each edge can be regarded as a bidirectional arc and every arc can be regarded as one unidirectional arc. In order to distinguish these two types of arc, the 'type' attribute is defined for every arc. If the 'type' attribute of an arc is larger than 0 , then it is a part of bidirectional arcs; else it is an unidirectional arc. For any two arcs corresponding to a required bidirectional arc, only one of them must be serviced in a feasible solution. 
3) Deadheading Cost: Deadheading means traveling without service. No matter whether a link in the given route is serviced or not, it will incur the predefined deadheading cost.

4) Initial Configuration: The number of trucks in each depot (initial configuration) is not considered in this paper. That is, there are an abundant number of trucks in every depot, but the total number of available trucks across all depots is $N_{2}$.

5) Service Time: For the sake of simplicity, only the traveling time of vehicles is considered as the service time. There is a linear relationship between the deadheading cost and the service time and the deadheading cost may be transformed to the traveling distance of trucks by multiplying by a coefficient $\alpha$.

6) Service Indicator: $f_{j}\left(\mu_{i j}\right)$ is a Boolean variable such that if arc $\mu_{i j}$ is serviced in route $l_{j}$, then $f_{j}\left(\mu_{i j}\right)=1$; else $f_{j}\left(\mu_{i j}\right)=0$.

\section{APPENDIX B}

\section{A SIMPLE EXAMPLE OF THE MULTIMARK OPERATION}

A simple example of the multimark operation is displayed in Fig. 12. In this example, there are four nodes, two depots (node 1 and node 3 ) and 12 arcs. For the sake of simplicity, a maximum deadheading cost of tours is employed to replace the constraint of maximum service time. From the final result of the mark operations, it can be seen that the total cost of the optimal solution, subject to the arc sequence of chromosome $(6,1,3,7)$, is 43 . The corresponding optimal solution is listed as follows.

1) Tour 1: 8, 6, 4, 1 (arcs 6 and 1 were serviced).

2) Tour 2: 10, 4, 11, 7 (arcs 4 and 7 were serviced).

In these tours, every number corresponds to the serial number of one corresponding arc. If there are three trucks available, then the total cost of optimal solutions would be decreased to 41. The corresponding optimal solution is listed as follows.

1) Tour 1: 5, 6 (arc 6 was serviced).

2) Tour 2: 2, 3, 9 (arcs 2 and 3 were serviced).

3) Tour 3: 8, 7 (arc 7 was serviced).

\section{REFERENCES}

[1] J. Araoz, E. Fernandez, and C. Zoltan, "Privatized rural postman problems," Comput. Oper. Res., vol. 33, no. 12, pp. 3432-3449, 2006.

[2] T. Bektas and S. Elmastas, "Solving school bus routing problems through integer programming," J. Oper. Res. Soc., vol. 58, no. 12, pp. 1599-1604, 2007.

[3] G. A. Tobin and R. Brinkmann, "The effectiveness of street sweepers in removing pollutants from road surfaces in Florida," J. Environ. Sci. Health (Part A), vol. 37, no. 9, pp. 1687-1700, 2002.

[4] E. Dijkgraaf and R. H. J. M. Gradus, "Fair competition in the refuse collection market," Appl. Econ. Lett., vol. 14, no. 10, pp. 701-704, 2007.

[5] H. Handa, L. Chapman, and X. Yao, "Robust route optimization for gritting/salting trucks: A CERCIA experience," IEEE Comput. Intell. Mag., vol. 1, no. 1, pp. 6-9, Feb. 2006.

[6] M. Dror, H. Stern, and P. Trudeau, "Postman tour on a graph with precedence relation on arcs," Networks, vol. 17, no. 3, pp. 283-294, 1987.

[7] H. S. Han, J. J. Yu, C. G. Park, and J. G. Lee, "Development of inspection gauge system for gas pipeline," Korean Soc. Mech. Eng. Int. J., vol. 18, no. 3, pp. 370-378, Mar. 2004.

[8] J. Tao, P. W. Que, and Z. S. Tao, "Magnetic flux leakage device for offshore oil pipeline defect inspection," Mater. Perform., vol. 44, no. 10 , pp. $48-51,2005$.
[9] H. I. Stern and M. Dror, "Routing electric meter readers," Comput. Oper. Res., vol. 6, no. 4, pp. 209-223, 1979.

[10] P. Lacomme, C. Prins, and W. Ramdane-Cherif, "Competitive memetic algorithms for arc routing problems," Ann. Oper. Res., vol. 131, nos. 1-4, pp. 159-185, 2004.

[11] B. Smith. (2004 Jan.). Highway Maintenance Network Management Policies and Standards, Regulation of Environment and Transport, Cambridgeshire County Council, Cambridge, U.K.

[12] B. L. Golden and R. T. Wong, "Capacitated arc routing problems," Networks, vol. 11, no. 3, pp. 305-315, 1981.

[13] C. Rego, "A subpath ejection method for the vehicle routing problem," Manage. Sci., vol. 44, no. 10, pp. 1447-1459, 1998.

[14] E. Minieka, "Chinese postman problem for mixed networks," Manage. Sci., vol. 25, no. 7, pp. 643-648, 1979.

[15] L. A. Moreira, J. F. Oliveira, A. M. Gomes, and J. Soeiro Ferreira, "Heuristics for a dynamic rural postman problem," Comput. Oper. Res., vol. 34, no. 11, pp. 3281-3294, Nov. 2007.

[16] G. Fleury, P. Lacomme, and C. Prins, "Evolutionary algorithms for stochastic arc routing problems," in Applications of Evolutionary Computing, Lecture Notes in Computer Science 3005. Berlin, Germany: Springer, 2004, pp. 501-512.

[17] A. A. Assad, B. L. Golden, and W.-L. Pearn, "The capacitated Chinese postman problem: Lower bounds and solvable cases," Amer. J. Math. Manage. Sci., vol. 7, nos. 1-2, pp. 63-88, 1987.

[18] M. Fischetti and P. Toth, "A polyhedral approach to the asymmetric traveling salesman problem," Manage. Sci., vol. 43, no. 11, pp. $1520-1536,1997$.

[19] A. Corberan, I. Plana, and J. M. Sanchis, "A branch and cut algorithm for the windy general routing problem and special cases," Networks, vol. 49, no. 4, pp. 245-257, 2007.

[20] P. Lacomme, C. Prins, and W. Ramdane-Cherif, "Evolutionary algorithms for periodic arc routing problems," Eur. J. Oper. Res., vol. 165 , no. 2 , pp. 535-553, Sep. 2005.

[21] R. Hirabayashi, N. Nishida, and Y. Saruwatari, "Node duplication lower bounds for the capacitated arc routing problems," J. Oper. Res. Soc. Jpn., vol. 35, no. 2, 119-133, 1992.

[22] W. L. Pearn, "New lower bounds for the capacitated arc routing problem," Networks, vol. 18, no. 12, pp. 181-191, 1988.

[23] S. Wohlk, "New lower bound for the capacitated arc routing problem," Comput. Oper. Res., vol. 33, no. 12, 3458-3472, 2006.

[24] J. M. Belenguer and E. Benavent, "The capacitated arc routing problem: Valid inequalities and facets," Comput. Optimizat. Applicat., vol. 10, no. 2, pp. 165-187, 1998.

[25] R. Hirabayashi, Y. Saruwatari, and N. Nishida, "Tour construction algorithm for the capacitated arc routing problem," Asia-Pacific J. Oper. Res., vol. 9, no. 2, pp. 155-175, 1992.

[26] B. L. Golden, J. S. DeArmon, and E. K. Baker, "Computational experiments with algorithms for a class of routing problems," Comput. Oper. Res., vol. 10, no. 1, pp. 47-59, 1983.

[27] W. L. Pearn, "Approximate solutions for the capacitated arc routing problem," Comput. Oper. Res., vol. 16, no. 6, pp. 589-600, 1989.

[28] G. Ulusoy, "The fleet size and mix problem for capacitated arc routing," Eur. J. Oper. Res., vol. 22, no. 3, pp. 329-337, Dec. 1985.

[29] W. L. Pearn, "Augment-insert algorithms for the capacitated arc routing problem," Comput. Oper. Res., vol. 18, no. 2, pp. 189-198, 1991.

[30] A. Hertz, G. Laporte, and M. Mittaz, "A tabu search heuristic for the capacitated arc routing problem," Oper. Res., vol. 48, no. 1, pp. 129-135, 2000.

[31] J. Branda and R. Eglese, "A deterministic tabu search algorithm for the capacitated arc routing problem," Comput. Oper. Res., vol. 35, no. 4, pp. 1112-1126, 2008.

[32] Y. Mei, K. Tang, and X. Yao, "A global repair operator for capacitated arc routing problem," IEEE Trans. Syst., Man, Cybern. B, Cybern., vol. 39, no. 3, pp. 723-734, Jun. 2009.

[33] A. Hertz and M. Mittaz, "A variable neighbourhood descent algorithm for the undirected capacitated arc routing problem," Transp. Sci., vol. 35, no. 4, pp. 425-434, 2001.

[34] P. Beullens, L. Muyldermans, D. Cattrysse, and D. Van Oudheusden, "A guided local search heuristic for the capacitated arc routing problem," Eur. J. Oper. Res., vol. 147, no. 3, pp. 629-643, Jun. 2003.

[35] P. P. Repoussis, C. D. Tarantilis, and G. Ioannou, "Arc-guided evolutionary algorithm for the vehicle routing problem with time windows," IEEE Trans. Evol. Comput., vol. 13, no. 3, pp. 624-647, Jun. 2009.

[36] K. Tang, Y. Mei, and X. Yao, "Memetic algorithm with extended neighborhood search for capacitated arc routing problems," IEEE Trans. Evol. Comput., vol. 13, no. 5, pp. 1151-1166, Oct. 2009. 
[37] R. W. Eglese, "Routing winter gritting vehicles," Discrete Appl. Math., vol. 48 , no. 3, pp. 231-244, 1994

[38] P. Lacomme, C. Prins, and M. Sevaux, "A genetic algorithm for a bi-objective capacitated arc routing problem," Comput. Oper. Res., vol. 33, no. 12, pp. 3473-3493, 2006.

[39] K. F. Doerner, R. F. Hartl, V. Maniezzo, and M. Reimann, "Applying ant colony optimization to the capacitated arc routing problem," in Proc. Ant Colony Optimization Swarm Intell., Lecture Notes in Computer Science 3172. Berlin, Germany: Springer, 2004, pp. 420-421.

[40] H. A. Eiselt, M. Gendreau, and G. Laporte, "Arc routing problems. Part II: The rural postman problem," Oper. Res., vol. 43, no. 3, pp. 399-414, 1995.

[41] G. Ghiani, F. Guerriero, G. Improta, and R. Musmanno, "Waste collection in southern Italy: Solution of a real-life arc routing problem," Int. Trans. Oper. Res., vol. 12, no. 2, 135-144, 2005.

[42] R. T. Sumichrast and I. S. Markham, "A heuristic and lower bound for a multidepot routing problem," Comput. Oper. Res., vol. 22, no. 10, pp. 1047-1056, 1995.

[43] J. Renaud, G. Laporte, and F. F. Boctor, "A tabu search heuristic for the multidepot vehicle routing problem," Comput. Oper. Res., vol. 23, no. 3, pp. 229-235, 1996.

[44] S. Salhi and M. Sari, "A multilevel composite heuristic for the multidepot vehicle fleet mix problem," Eur. J. Oper. Res., vol. 103, no. 1, pp. 95-112, Nov. 1997.

[45] W. Ho, G. T. S. Ho, P. Ji, and H. C. W. Lau, "A hybrid genetic algorithm for the multidepot vehicle routing problem," Eng. Applicat. Artif. Intell., vol. 21, no. 4, pp. 548-557, Jun. 2008.

[46] R. Dondo and J. Cerda, "A cluster-based optimization approach for the multidepot heterogeneous fleet vehicle routing problem with time windows," Eur. J. Oper. Res., vol. 176, no. 3, pp. 1478-1507, Feb. 2007.

[47] A. Lim and F. Wang, "Multidepot vehicle routing problem: A one-stage approach," IEEE Trans. Autom. Sci. Eng., vol. 2, no. 4, pp. 397-402, Oct. 2005.

[48] C. T. Su, "Dynamic vehicle control and scheduling of a multidepot physical distribution system," Integr. Manuf. Syst., vol. 10, no. 1, pp. 56-65, 1999.

[49] A. Amberg, W. Domschke, S. Voß, "Multiple center capacitated arc routing problems: A tabu search algorithm using capacitated trees," Eur. J. Oper. Res., vol. 124, no. 2, pp. 360-376, Jul. 2000.

[50] T. H. Cormen, C. L. Leiserson, and M. L. Rivest, "Single-source shortest paths," in Introduction to Algorithms. Cambridge, MA: MIT Press, 1990, pp. 491-527.

[51] C. J. Chung and R. G. Reynolds, "A testbed for solving optimization problems using cultural algorithm," in Proc. 5th Annu. Conf. Evol. Program., Cambridge, MA: MIT Press, 1996, pp. 225-236.

[52] J. Branke, "Memory-enhanced evolutionary algorithms for dynamic optimization problems," in Proc. Congr. Evol. Comput., Piscataway, NJ: IEEE Press, 1999, pp. 1875-1882.

[53] S. J. Louis and J. McDonnell, "Learning with case-injected genetic algorithms," IEEE Trans. Evol. Comput., vol. 8, no. 4, pp. 316-328, Aug. 2004.

[54] R. S. Michalski, "Learnable evolution model: Evolution process guided by machine learning," Mach. Learning, vol. 38, no. 1, pp. 9-40, 2000.

[55] N. B. Ho, J. C. Tay, and E. M. K. Lai, "An effective architecture for learning and evolving flexible job-shop schedules," Eur. J. Oper. Res., vol. 179 , no. 2, pp. 316-333, Jun. 2007.

[56] B. K. S. Cheung, A. Langevin, and B. Villeneuve, "High performing evolutionary techniques for solving complex location problems in industrial system design," J. Intell. Manuf., vol. 12, nos. 5-6, pp. 455-466, 2001.

[57] J. Demsar, "Statistical comparisons of classifiers over multiple data sets," J. Mach. Learning Res., vol. 7, pp. 1-30, Jan. 2006.

[58] J. M. Belenguer and E. Benavent, "A cutting plane algorithm for the capacitated arc routing problem," Comput. Oper. Res., vol. 30, no. 5, pp. 705-728, 2003.

[59] M. Kiuchi, Y. Shinano, R. Hirabayashi, and Y. Saruwatari, "An exact algorithm for the capacitated arc routing problem using parallel branch and bound method," in Proc. Abstracts 1995 Spring Natl. Conf. Oper. Res. Soc. Jpn., pp. 28-29.

[60] E. Benavent, V. Campos, A. Corberán, and E. Mota, "The capacitated Chinese postman problem: Lower bounds," Networks, vol. 22, no. 7 , pp. 669-690, 1992.

[61] L. Y. O. Li and R. W. Eglese, "An interactive algorithm for vehicle routing for winter-gritting," J. Oper. Res. Soc., vol. 47, no. 2 , pp. $217-228,1996$

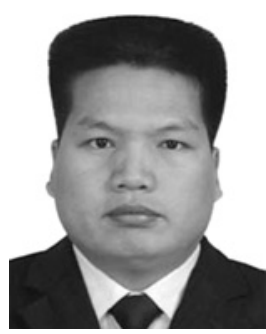

Lining Xing received two B.S. degrees in economics and science from Xi' an Jiaotong University, Shaanxi, China, in 2002. Currently, he is pursuing the $\mathrm{Ph} . \mathrm{D}$. degree from the College of Information Systems and Management, National University of Defense Technology, Changsha, China.

His research interests include management decision making, simulation optimization, and artificial intelligence.

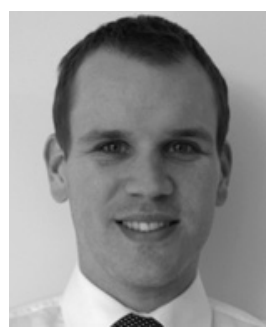

Philipp Rohlfshagen received the B.S. degree in computer science and artificial intelligence from the University of Sussex, Brighton, U.K., in 2003, and the M.S. degree in natural computation and the $\mathrm{Ph} . \mathrm{D}$. degree in evolutionary computation from the University of Birmingham, Birmingham, U.K., in 2004 and 2007, respectively.

$\mathrm{He}$ is currently a Research Fellow at the Center of Excellence for Research in Computational Intelligence and Applications, School of Computer Science, University of Birmingham, where he is studying the theoretical aspects of evolutionary algorithms for dynamic optimization problems. His research interests include combinatorial optimization, computational complexity, evolutionary computation, global optimization, algorithm design, and molecular genetics.

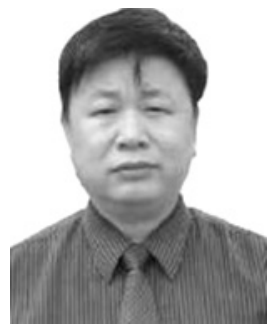

Yingwu Chen received the B.S. degree in automation, the M.S. degree in system engineering, and the $\mathrm{Ph} . \mathrm{D}$. degree in engineering from the National University of Defense Technology (NUDT), Changsha, China, in 1984, 1987, and 1994, respectively.

He was a Lecturer from 1989 to 1994, and an Associate Professor from 1994 to 1999 at NUDT. Since 1999, he has been a Distinguished Professor and the Director of the Department of Management Science and Engineering, College of Information Systems and Management, NUDT, where he focuses on management theory and its applications. He has authored more than 60 research publications. His current research interests include assistant decisionmaking systems for planning, decision-making systems for project evaluation, management decisions, and artificial intelligence.

Dr. Chen is the Editor of the Principle of System Engineering (Press of National University of Defense Technology), and Technology of Quantificational Analysis (China Renmin University Press).

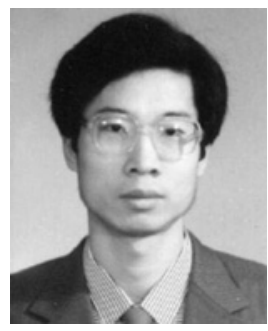

Xin Yao (M'91-SM'96-F'03) received the B.S. degree from the University of Science and Technology of China (USTC), Hefei, China, in 1982, the M.S. degree from the North China Institute of Computing Technology, Beijing, China, in 1985, and the Ph.D. degree from USTC in 1990, all in computer science.

$\mathrm{He}$ is currently a Chair (Full Professor) of Computer Science and the Director of the Center of Excellence for Research in Computational Intelligence and Applications, University of Birmingham, U.K. He is a Distinguished Lecturer of IEEE Computational Intelligence Society, a Distinguished Visiting Professor at USTC, and a Visiting Professor at Nanjing University, Xidian University and Northeast Normal University. He has been an invited keynote speaker at more than 50 international conferences, and has more than 300 refereed research publications in evolutionary computation and neural network ensembles. His research interests include evolutionary computation, neural network ensembles, global optimization, data mining, computational time complexity of evolutionary algorithms, and real-world applications. In addition to basic research, he works closely with many industrial partners on various real-world problems.

Dr. Yao was an Editor-in-Chief of IEEE TRANSACTIONS ON EVOLUTIONARY COMPUTATION from 2003 to 2008, and is an Associate Editor or an Editorial Board Member of ten other international journals. He is the Editor of the World Scientific Book Series on Advances in Natural Computation, and a Guest Editor of several journal special issues. 